
work is properly cited.

\title{
The biology of ergothioneine, an antioxidant nutraceutical
}

\author{
Irina Borodina ${ }^{1}$, Louise C. Kenny ${ }^{2}$, Cathal M. McCarthy ${ }^{3,4}$, Kalaivani Paramasivan ${ }^{1}$, Etheresia Pretorius ${ }^{5}$, \\ Timothy J. Roberts ${ }^{5,6}$, Steven A. van der Hoek ${ }^{1}$ and Douglas B. Kell ${ }^{1,5,6 *}$ \\ ${ }^{1}$ The Novo Nordisk Foundation Center for Biosustainability, Building 220, Chemitorvet 200, Technical University of Denmark, \\ 2800 Kongens Lyngby, Denmark \\ ${ }^{2}$ Department of Women's and Children's Health, Institute of Translational Medicine, University of Liverpool, Crown Street, \\ Liverpool L8 $7 S S$, UK \\ ${ }^{3}$ Irish Centre for Fetal and Neonatal Translational Research (INFANT), Cork University Maternity Hospital, Cork, Republic of \\ Ireland \\ ${ }^{4}$ Department of Pharmacology and Therapeutics, Western Gateway Building, University College Cork, Cork, Republic of Ireland \\ ${ }^{5}$ Department of Physiological Sciences, Faculty of Science, Stellenbosch University, Stellenbosch, Private Bag X1 Matieland, \\ 7602, South Africa \\ ${ }^{6}$ Department of Biochemistry, Institute of Integrative Biology, Faculty of Health and Life Sciences, University of Liverpool, Crown \\ Street, Liverpool L69 7ZB, UK
}

\begin{abstract}
Ergothioneine (ERG) is an unusual thio-histidine betaine amino acid that has potent antioxidant activities. It is synthesised by a variety of microbes, especially fungi (including in mushroom fruiting bodies) and actinobacteria, but is not synthesised by plants and animals who acquire it via the soil and their diet, respectively. Animals have evolved a highly selective transporter for it, known as solute carrier family 22 , member 4 (SLC22A4) in humans, signifying its importance, and ERG may even have the status of a vitamin. ERG accumulates differentially in various tissues, according to their expression of SLC22A4, favouring those such as erythrocytes that may be subject to oxidative stress. Mushroom or ERG consumption seems to provide significant prevention against oxidative stress in a large variety of systems. ERG seems to have strong cytoprotective status, and its concentration is lowered in a number of chronic inflammatory diseases. It has been passed as safe by regulatory agencies, and may have value as a nutraceutical and antioxidant more generally.
\end{abstract}

Key words: Ergothioneine: SLC22A4: Oxidative stress: Cytoprotectants: Nutraceuticals

(Received 1 July 2019; revised 20 November 2019; accepted 25 November 2019)

\section{Introduction}

Most of the classical vitamins such as vitamins $A, B_{1}, B_{2}, B_{3}, C, D$, etc., were discovered by means of the fact that an inadequacy in their supply led to overt forms of deficiency disease such as blindness, beri-beri, pellagra, scurvy, rickets and so on. Consequently, it was easy to establish those food sources that contained such vitamins, since they relieved or prevented the relevant syndromes ${ }^{(1,2)}$. It is correspondingly hard, by these means, to detect the presence of a vitamin if it is present in virtually every foodstuff that an individual consumes. Recently, however, L-(+)-ergothioneine, hereafter ergothioneine (ERG), has emerged ${ }^{(3-10)}$ as an important nutrient, and indeed possible vitamin $^{(3)}$, that has precisely these properties of a very widespread occurrence coupled, commonly, to a functional undersupply.

A related class of nutrient, which has not been demonstrated as necessary or essential for life yet provides health benefits when added at levels greater than a normal diet generally provides, has come to be known as nutraceuticals, a coinage based on an amalgamation of 'nutrition' and 'pharmaceutical' ${ }^{\text {(11). }}$. Interest in such nutraceuticals, also known as 'functional foods', has increased enormously over the last few decades ${ }^{(11-22)}$ as our understanding of the important roles of diet in health has improved. However, the enthusiasm for such products has not always been matched by the extent or quality of the evidence for their efficacy ${ }^{(20,23-28)}$.

Since ERG classes as a nutraceutical, it seems timely to bring together the extensive but widespread knowledge of its biology so that it may be made more widely available, and that is the purpose of this review.

\section{Discovery and structure}

ERG is a somewhat unusual betaine amino acid. It was discovered by Charles Tanret in 1909 while investigating the ergot

Abbreviations: egt, early G1 transcript; ERG, ergothioneine; $\mathrm{O}_{2}{ }^{--}$, oxygen radical; $\mathrm{OH}^{\bullet}$, hydroxyl radical; SLC22A4, solute carrier family 22 , member 4.

* Corresponding author: Douglas B. Kell, email dbk@liv.ac.uk 
Fig. 1. Structures of ergothioneine and related molecules. For a colour figure, see the online version of the paper.

fungus Claviceps purpurea ${ }^{(29,30)}$. It is also known as 2-mercaptohistidine trimethylbetaine, and its formal International Union of Pure and Applied Chemistry (IUPAC) name is (2S)-3-(2-thioxo2,3-dihydro-1H-imidazol-4-yl)-2-(trimethylammonio)propanoate. It is an L-histidine derivative that is $\mathrm{N}^{\alpha}, \mathrm{N}^{\alpha}, \mathrm{N}^{\alpha}$-trimethyl-L-histidine in which the hydrogen at position 2 on the imidazole ring is replaced by a mercapto group. Its structure ${ }^{(31)}$, and those of some related molecules, is given in Fig. 1, indicating that is a tautomer that has both a thiol and a thione form. Although it is a thiol, and hence an antioxidant ${ }^{(32,33)}$, the thione tautomer is predominant at physiological $\mathrm{pH}^{(34,35)}$, and this makes it unusually resistant to autoxidation, i.e. simple oxidation by molecular $\mathrm{O}_{2}{ }^{(32,36-38)}$. Its midpoint potential for a thiol is consequently unusually high, being $+0.06 \mathrm{~V} v$. -0.2 to $-0.4 \mathrm{~V}$ for typical thiols including glutathione $^{(4,39-41)}$ and mycothiol ${ }^{(42,43)}$, and $-0 \cdot 193 \mathrm{~V}$ for the also somewhat oxidising thiol cofactor coenzyme $\mathrm{M}$, which is 2-mercaptoethanesulfonate ${ }^{(44)}$. Its reaction with hydroxyl radicals $\left(\mathrm{OH}^{*}\right)$ is virtually instantaneous, while it reacts only more slowly with $\mathrm{H}_{2} \mathrm{O}_{2}$ and/or $\mathrm{O}_{2}{ }^{-(38)}$. Its Se equivalent is known as selenoneine and also has strong antioxidant properties $^{(45-52)}$, but is not otherwise discussed here.

From a pharmaco-chemical point of view ERG is also unusual, since - using our standard substructure analysis ${ }^{(53,54)}$ in $\mathrm{KNIME}^{(55)}$ - we note that just two drugs marketed for human consumption (the anti-thyroxine-production drug methimazole and its pro-drug carbimazole, Fig. 1), and no endogenous genome-encoded metabolites from Recon $2^{(56)}$ contain the imidazole-2-thione substructure ${ }^{(57)}$. This said, a good many fungicides do contain the benzimidazole substructure ${ }^{(58)}$, and a variety of benzothiazoles are used as dyes.

\section{Biosynthesis and phylogenetic distribution}

A particular feature of ERG is that although it is more or less universally distributed among higher organisms, none of them - as is consistent with the idea that it may in fact be a vitamin requiring exogeneous sources - can in fact biosynthesise it. The chief organisms capable of its synthesis are fungi and certain yeasts ${ }^{(59,60)}$, though actinobacteria and certain other micro-organisms ${ }^{(60-66)}$, including the slime mould Physarum polycephalum ${ }^{(65)}$, cyanobacteria $^{(67-71)}$ and methylotrophs ${ }^{(72)}$ are also naturally capable of its production. The related mycothiol is typically ten times more concentrated in actinobacteria than is $\mathrm{ERG}^{(73)}$, and its biosynthetic pathway might provide an antitubercular drug target. Other organisms acquire ERG through transportermediated uptake. Thus higher plants contain it but do not biosynthesise it $^{(74)}$; instead they and other organisms ${ }^{(68,75)}$ take it up from fungal production in the soil ${ }^{(76-79)}$, and possibly via actinobacterial $^{(80)}$ or fungal ${ }^{(80,81)}$ symbionts. Animals are also considered not to biosynthesise it ${ }^{(82,83)}$, and accumulate it using a particular transporter, detailed below, via the plants and animals that they eat. Although not easy, it is possible to raise animals such as pigs on a diet such as casein, sucrose, lard, butter and salts that is considered to lack ERG; such animals are said to have undetectable levels of the compound ${ }^{(84)}$, and rats treated similarly have reproduced ${ }^{(85,86)}$. However, we do not know the minimum amount and its location that animals need, and these are old experiments that need to be repeated with modern techniques with lower detection limits. Only then might we have a definitive statement as to whether ERG is absolutely required as a true vitamin or not, and if so in what amounts for health. In a similar vein, ERG can be present in cell culture media and cells with organic cation transporter N1 (OCTN1)/solute carrier family 22 , member 4 (SLC22A4) can accumulate it ${ }^{(87)}$, a fact little considered to date in cell culture studies.

To the extent that ERG is a 'secondary' metabolite, defined ${ }^{(88)}$ as a molecule whose synthesis has a relatively restricted distribution in different organisms, the biosynthetic pathways diverge from primary metabolism via the amino acids histidine, cysteine and methionine ${ }^{(89-94)}$. Thus (Fig. 2), histidine is trimethylated 


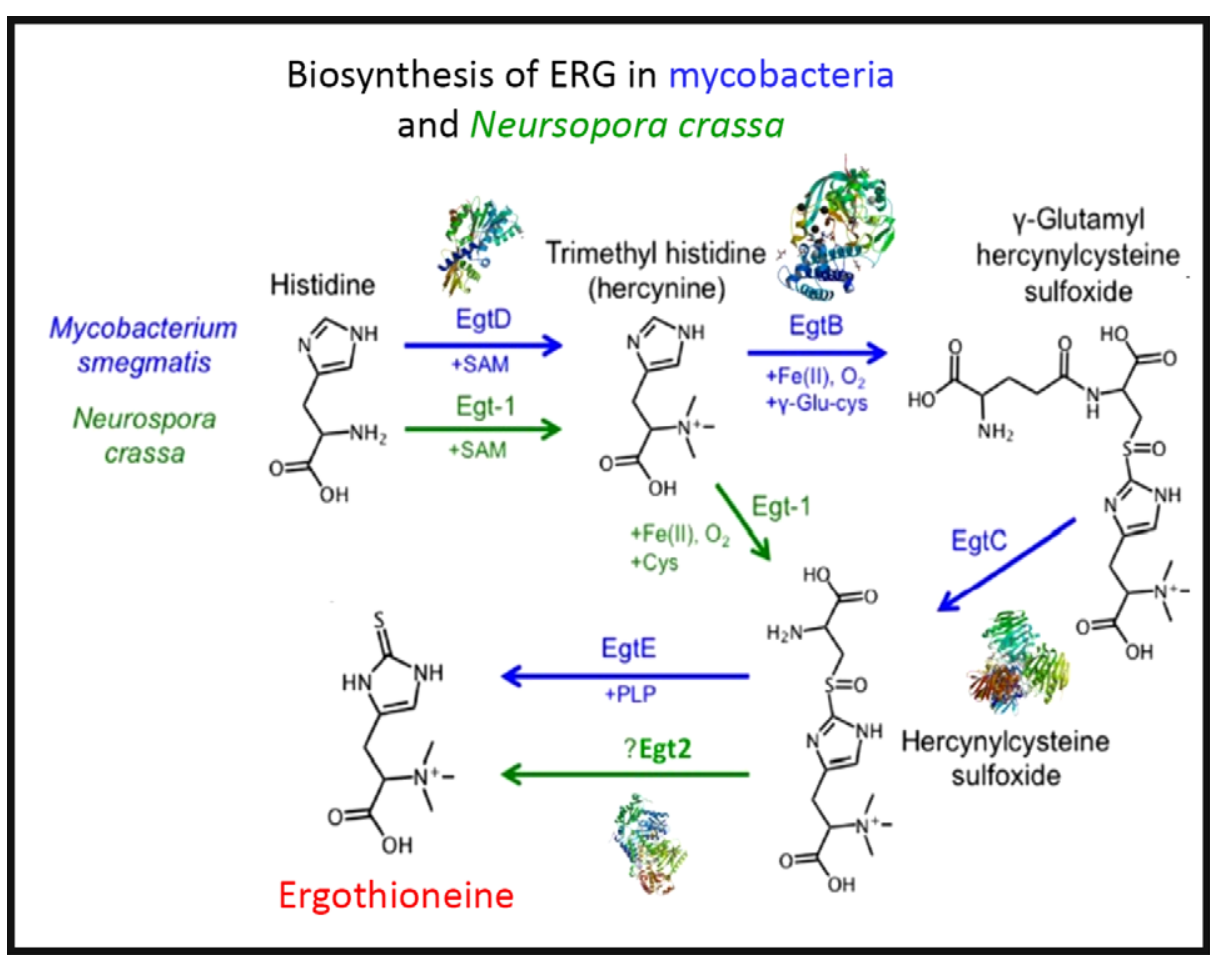

Fig. 2. The two main pathways of aerobic ergothioneine (ERG) biosynthesis, noting the relevant enzymes and thumbnails of three-dimensional structures where known. SAM, S-adenosyl methionine. For a colour figure, see the online version of the paper.

Table 1. Biosynthesis of ergothioneine in various non-recombinant microorganisms

\section{Organism}

Aspergillus fumigatus

Aspergillus niger

Aureobasidium pullulans

Burkholderia pseudomallei

Chlorobium limicola

Claviceps purpurea

Lactobacillus casei

Methylobacterium aquaticum

Mycobacterium tuberculosis

Neurospora crassa

Schizosaccharomyces pombe

Streptomyces coelicolor

using $S$-adenosyl methionine to form trimethyl histidine, also known as hercynine ${ }^{(95,96)}$. This reacts oxidatively with cysteine to form hercynylcysteine sulfoxide ${ }^{(97)}$, which is converted to ERG. In some organisms, hercynine takes a more convoluted route via $\gamma$-glutamylhercynylcysteine sulfoxide (Fig. 2) ${ }^{(94)}$. Table 1 provides references for different organisms. An excellent phylogenetic analysis is given by Jones et al. ${ }^{(60)}$. In more recent work, it has been suggested that ERG was probably first biosynthesised by anaerobes using a slightly different route that converts hercynine directly to $\mathrm{ERG}^{(98-100)}$, and that was later repurposed.

Three-dimensional structures are known for a number of the relevant enzymes, including mycobacterial $\mathrm{EgtB}^{(101)}$ for example, PDB 4XBE, EgtC ${ }^{(102)}$ for example, PDB 4ZFJ, EgtD ${ }^{(103-105)}$ for example, PDB 4PIM, and Neurospora crassa early G1 transcript 2 (egt2) which is like egtE ${ }^{(106)}$ for example, PDB 5UTS.
Very recently, EgtB from Candidatus Chloracidobacterium thermophilum was crystallised ${ }^{(107)}$, and engineered towards Egt1 activity. Thumbnails are given in Fig. 2. Egt1 from $N$. crassa is 876 amino acids long ${ }^{(108)}$, while egtD (from Mycobacterium tuberculosis $\left.{ }^{(109)}\right)$ is just 321 amino acids long; since the $\mathrm{N}$-terminal sequences are well conserved (Fig. 3), this implies an extra C-terminal domain catalysing the production of hercynylcysteine sulfoxide from hercynine.

In addition, enantiopure L-ERG has been synthesised chemically(76,110-112), and by fermentation of genetically engineered micro-organisms (Table 2). Initial efforts in ERG synthesis were carried out in Schizosaccahromyces pombe using egt1 overexpression under an inducible promoter. The $\mathrm{N}$ starvation and glucose starvation conditions causing long quiescence led to the maximum ERG production of $1606 \cdot 3 \mu \mathrm{m}$ while the wildtype strain produced $0.3 \mu \mathrm{M}^{(50)}$. Methylobacterium aquaticum strain 22A was engineered by expressing an additional copy of egtBD genes and by deleting the gene encoding histidine ammonia lyase, which degrades an ERG precursor L-histidine. The resulting strain produced up to $7 \cdot 0 \mathrm{mg}$ EGT/g dry cell weight and $100 \mu \mathrm{g}$ EGT $/ 5 \mathrm{ml}$ per $7 \mathrm{~d}$ in test-tubes ${ }^{(113)}$. The filamentous fungus Aspergillus oryzae has also been engineered to produce ERG by expression of egt 1 and egt 2 genes from $N$. crassa, resulting in $231 \mathrm{mg}$ ERG per $\mathrm{kg}$ of solid media ${ }^{(114)}$.

Expression of egtBCDE genes from Mycobacterium smegmatis in Escherichia coli and optimisation of medium composition has led to $24 \mathrm{mg} / \mathrm{l}$ or $104 \mu \mathrm{m}$ of secreted $\mathrm{ERG}^{(115)}$. The egtA gene from $M$. smegmatis was not expressed because $E$. coli contains a homologous glutamate-cysteine ligase encoded by gshA and involved in glutathione biosynthesis. 


\section{Alignment of $N$. crassa Egt1 and the N-terminal part of $M$. tuberculosis EgtD}

Q7RX33 EGT1_NEUCR P9WN46 EGTD_MYCTO

Q7RX33 EGT1 NEUCR P9WN46 EGTD-MYCTO

Q7RX33 EGT1 NEUCR P9WN46 EGTD_MYCTO

Q7RX33 EGT1 NEUCR P9WN46 EGTD ${ }^{-}$MYCTO

Q7RX33 EGT1 NEUCR P9WN46 EGTD_MYCTO

Q7RX33 EGT1 NEUCR P9WN46 EGTD_MYCTO

Q7RX33 EGT1 NEUCR P9WN46 EGTD_MYCTO
1 MPSAESMTPSSALGQLKATGQHVLSKLQQQTSNADI I DIRRVAVE INLKTE I TSMFRPKD

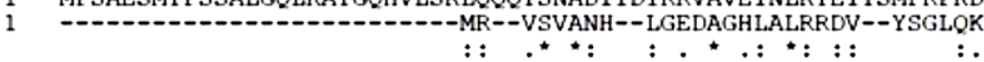

61 GPRQLPTLLLYNERGLQLFER I TYLEEYYLTNDE I KI LTKHATEMASF I PSGAMI IELGS

29 TPKSLPPKWFYDTVGSELFDQITRLPEYYPTRAEAE I LRARSAEVASACR-ADTLVELGS

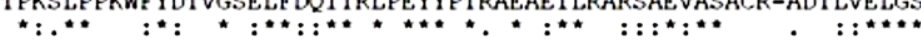

121 GNLRKVNLLLEALDNAGKAIDYYALDLSREELERTLAQ-VPSYKHVKCHGLLGTYDDGRD GTSEKTRMLLDALRHRGSLRRFVPFDVDASVLSATATAIQREYSGVE INAVCGDFEEHLT

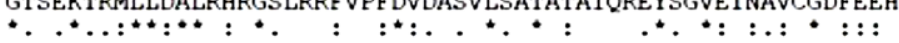

180 WLKAPEN INKQKCI LHLGSS IGNFNRSDAATFLKGFTDVLGPNDKML I GVDACNDPARVY E---I PRGGRRLFVFLGSTIGNLTPGPRAQFLTALAGVMRPGDSLLLGTDLVKDAARLV

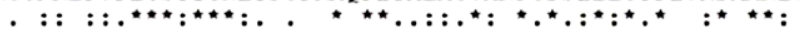

240 HAYNDKVGITHEF I LNGLRNANEI I GETAF I EGDWRV IGEYVYDEEGGRHQAFY-APTRD 204 RAYDDPGGVTAQFNRNVLAVINRELEAD-FDVDAFQHVARWNSAEE--RIEMWLRADGRQ 299 TMVMGELI-----RSHDRIQIEQSLKYSKEESERLWSTAGLEQVSEWTY-GNEYGLHLLA RVRVGALDLTVDFDAGEEMTEVSCKFRPQAVGAELAAAGLHRIRWWTDEAGDFGLSLAA

353 KSRMSFSLI PSVYARSALPTLDDWEAL.WATWDVVTRQMLPQEELLEKPIKLRNACIFYLG 321

Fig. 3. Alignment of Neurospora crassa Egt1 and N-terminal part of Mycobacterium tuberculosis EgtD. For a colour figure, see the online version of the paper.

Table 2. Fermentative production of ergothioneine in recombinant micro-organisms

\begin{tabular}{|c|c|c|c|c|}
\hline Organism & Genetic modification(s) & Titre & Conditions & Reference \\
\hline Aspergillus oryzae & $\begin{array}{l}\text { Expression of egt1 and egt2 genes from } \\
\text { Neurospora crassa }\end{array}$ & $231.0 \mathrm{mg} / \mathrm{kg}$ of media & Cultivation on solid, rice-based medium & (114) \\
\hline Escherichi coli & $\begin{array}{l}\text { Expression of egtBCDE genes from } \\
\text { Mycobacterium smegmatis }\end{array}$ & $\begin{array}{l}24 \text { (SEM 4) mg/l } \\
\text { (extracellular) }\end{array}$ & $\begin{array}{l}\text { Shake flasks. Medium supplemented } \\
\text { with yeast extract, His, Met, } \\
20 \text { mm-thiosulfate as sulfur source for } \\
\text { L-cysteine synthesis. IPTG for inducing } \\
\text { heterologous gene expression }\end{array}$ & (115) \\
\hline Escherichia coli & $\begin{array}{l}\text { Expression of the following genes: } \\
\text { egtABCDE from } M \text {. smegmatis, } \\
\text { altered } c y s E \text { gene encoding serine } \\
\text { acetyltransferase feed-back resistant } \\
\text { to Cys, native yde } D \text { gene encoding } \\
\text { inner membrane Cys exporter, altered } \\
\text { serA gene encoding L-serine } \\
\text { Feedback inhibition-insensitive mutant } \\
\text { of d-3-phosphoglycerate } \\
\text { dehydrogenase. Deletion of metJ } \\
\text { gene encoding transcriptional } \\
\text { repressor }\end{array}$ & $1.3 \mathrm{~g} / \mathrm{l}$ (extracellular) & $\begin{array}{l}\text { Fed-batch in 3-litre bioreactor, } 216 \mathrm{~h} \text {. } \\
\text { Complex medium supplemented with } \\
\text { IPTG, ammonium ferric citrate, } \\
\text { pyridoxine, Met, His, and thiosulfate }\end{array}$ & (116) \\
\hline $\begin{array}{l}\text { Methylobacterium } \\
\text { aquaticum strain } 22 \mathrm{~A}\end{array}$ & $\begin{array}{l}\text { Additional copy of egtBD expressed } \\
\text { from a plasmid, deletion of histidine } \\
\text { ammonia-lyase (hutH) gene }\end{array}$ & $20 \mathrm{mg} / \mathrm{l}$ & $\begin{array}{l}\text { Test-tubes. Complex medium with } \\
\text { methanol }\end{array}$ & (113) \\
\hline $\begin{array}{l}\text { Saccharomyces } \\
\text { cerevisiae }\end{array}$ & & $\begin{array}{l}598(\mathrm{sD} 18) \mathrm{mg} / \mathrm{l} \text {, of } \\
\text { which } 59 \% \text { was } \\
\text { extracellular }\end{array}$ & $\begin{array}{l}\text { Fed-batch fermentation in } 1 \text {-litre } \\
\text { bioreactor, } 84 \mathrm{~h} \text {. Defined medium } \\
\text { supplemented with arginine, histidine, } \\
\text { methionine and pyridoxine }\end{array}$ & $(570)$ \\
\hline $\begin{array}{l}\text { Schizosaccahromyces } \\
\text { pombe }\end{array}$ & $\begin{array}{l}\text { egt1 overexpression under inducible } \\
\text { promoter }\end{array}$ & $368 \mathrm{mg} / \mathrm{l}$ & $\begin{array}{l}\mathrm{N} \text { and glucose starvation. Cultivation } \\
\text { method not given }\end{array}$ & (50) \\
\hline
\end{tabular}

IPTG, isopropyl $\beta$ - d-1-thiogalactopyranoside.

In a follow-up study, the authors expressed egt $A$ from M. smegmatis and it had a positive effect on ERG production. Furthermore, they enhanced cysteine and $S$-adenosine methionine biosynthesis and obtained $1.3 \mathrm{~g} / \mathrm{l}$ or ERG in a fed-batch fermentation $^{(116)}$, achieving currently the highest titre reported for heterologous ERG production.

Recently, we reported the engineering of baker's yeast Saccharomyces cerevisiae for the production of $\mathrm{ERG}^{(117)}$. 
S. cerevisiae has a generally recognised as safe (GRAS) status and has been exploited for the commercial production of several nutraceutical compounds ${ }^{(118)}$; it is thus a highly attractive host for the production of ERG. We have tested sixteen different pathway variants, nine containing only fungal genes, one with bacterial genes from $M$. smegmatis, and six hybrid pathway variants containing both fungal and bacterial transgenes. The best-performing strain contained egt 1 from $N$. crass $a$ and egt2 from $C$. purpurea. The composition of the medium was improved using a fractional factorial design. Fed-batch cultivation resulted in 598 (SD 18) mg/l ERG after an 84-h fermentation. Some $60 \%$ of the measured ERG was extracellular and the rest accumulated in the cells. Table 2 summarises the various recombinant expression hosts that have been used.

The distribution of solute transporters between tissues in differentiated organisms is particularly heterogeneous ${ }^{(119)}$, and it is to be expected that both SLC22A 4 and ERG might also be distributed heterogeneously as well. This is indeed the case, their distribution being especially high in tissues that are considered to have the potential for oxidative stress ${ }^{(4)}$, such as erythrocytes $^{(120-129)}$, bone marrow ${ }^{(130)}$, liver and kidney ${ }^{(85,131)}$, seminal fluid $^{(132,133)}$ and the lens and cornea of the eyes ${ }^{(134)}$. It may also be accumulated in the $\mathrm{CNS}^{(135,136)}$.

Finally, here, we note - as with the activity of the 'master Fe regulator' hepcidin ${ }^{(137-141)}$, that acts chiefly via the ferrous Fe transporter ferroportin - that the action of a transporter in concentrating a substance in one tissue will typically lead to its depletion from another. Consequently, it is necessary to measure all relevant compartments to assess whether a molecule such as ERG, whose distribution is strictly transporter-mediated, is protective against a particular disease/effect or otherwise in a particular place or case.

\section{SLC22A4: the ergothioneine transporter}

Although this view remains controversial, even hydrophobic molecules do not normally 'float across' whatever phospholipid bilayer portion of cells may be untrammelled by proteins. Xenobiotics in particular need to 'hitchhike' on protein transporters that have presumably evolved for 'natural' substrates but that are capable of their uptake ${ }^{(142-152)}$. While transporters seem to have remained somewhat understudied ${ }^{(153)}$, those transporters involved in uptake and encoded by the human genome are now catalogued formally as SLC for solute carriers ${ }^{(154,155)}$, with efflux transporters mainly being classed as ABC families ${ }^{(156)}$.

One solute carrier, previously known as organic cation transporter N1 (OCTN1) ${ }^{(157,158)}$, and now known as SLC22A4 (the human version is Uniprot Q9H015), a 551-amino-acid transporter with three glycosylation sites, is of special interest. It had been designated as a transporter of carnitine and of the (non-physiological) tetraethylammonium cation. However, in a really groundbreaking paper, Gründemann et al. ${ }^{(130)}$ recognised that the rates observed (using radioisotopes) were too small to be physiologically meaningful, and using a method that we would now refer to as 'untargeted metabolomics,(159-164), they incubated two kinds of HEK293 cells in serum. The first were normal cells, that, as with many transporters ${ }^{(119)}$, do not in fact express SLC22A4 at significant levels, while the second had been engineered to overexpress the transporter. They then simply looked for those molecules that were most differentially taken up, a molecule called stachydrine, also known as proline betaine, being the main one observed, Stachydrine is a constituent of citrus juices ${ }^{(165-167)}$. Some elementary cheminformatics based on structure similarity searches ${ }^{(57,168)}$ indicated that ERG, as a betaine, was indeed similar to stachydrine. Incubating the cells just with ERG showed that it was taken up about 100 times more quickly than was tetraethylammonium, leading to the designation of SLC22A4 as 'the' ERG transporter ${ }^{(130)}$. Subsequent work $^{(87,169-172)}$ has confirmed and reinforced this view of SLC22A 4 and its homologues ${ }^{(173)}$ as having significant specificity for ERG, and weak activity for various drugs ${ }^{(174-177)}$. It is concentrative, coupled in humans to influx of 2 or $3 \mathrm{Na}^{+}$ions per ERG transported ${ }^{(130)}$. Interestingly, it is up-regulated chronobiologically just before meal times ${ }^{(175)}$. The rat and human orthologues are interchangeable ${ }^{(178)}$. Tissue levels of ERG depend on an exogenous supply ${ }^{(179)}$, but are then well correlated with the expression levels of SLC22A4(3,180). SLC22A4 expresses well even in microbial systems ${ }^{(181)}$, and is widely tolerant of amino acid substitutions ${ }^{(182)}$. As yet, no other transporter with significant activity for ERG in humans is known, making it a potentially interesting drug target ${ }^{(183,184)}$.

\section{Expression patterns}

SLC22A4 is known to express in the intestinal lumen ${ }^{(185)}$, acting to take up ERG, as well as some xenobiotics including pyrilamine, quinidine and verapamil, and having multiple known but weak inhibitors.

Fig. 4 shows the expression of the transcript for SLC22A4 in fifty-six cell lines using previous data ${ }^{(119)}$ taken from the human protein atlas ${ }^{(186)}$, indicating a range in expression levels between different cell lines of more than 4000-fold, a number not atypical for human transporters ${ }^{(119)}$. Tissue expression data are given in Fig. S4 of O'Hagan et al. ${ }^{(119)}$.

The intracellular expression patterns are as yet uncertain, with early claims for a mitochondrial expression ${ }^{(86,187-190)}$ being based on very weak and contradictory evidence ${ }^{(8)}$. However, while the cellular uptake of ERG does require plasma membrane expression, the latest version of the protein atlas indicates mitochondrial expression as well ${ }^{(191)}$. However, as is well known, antibody specificities are rarely either known or absolute ${ }^{(192-198)}$. Thus, relying on antibody evidence alone is rather hazardous, and, as mentioned before ${ }^{(8)}$, mitochondrial transporters have an SLC25 family designation ${ }^{(199,200)}$. Definitive measurements on the uptake or otherwise of ERG into isolated mitochondria, or indeed into other organisms that cannot make it, are eagerly awaited.

\section{Evolution and phylogenetic distribution of SLC22A4}

Phylogenetic analyses ${ }^{(201,202)}$ indicate that homologues of SLC22A4, a relative of the major facilitator superfamily 2, exist only in vertebrate animals, especially mammals, birds and fish, with occasional examples in reptiles (for example, Xenopus spp.).

In practice, it appears that the transporters responsible for the uptake of some $85 \%$ of pharmaceutical drugs actually evolved to 


\section{Expression of SLC22A4 in ranked order of cell lines}

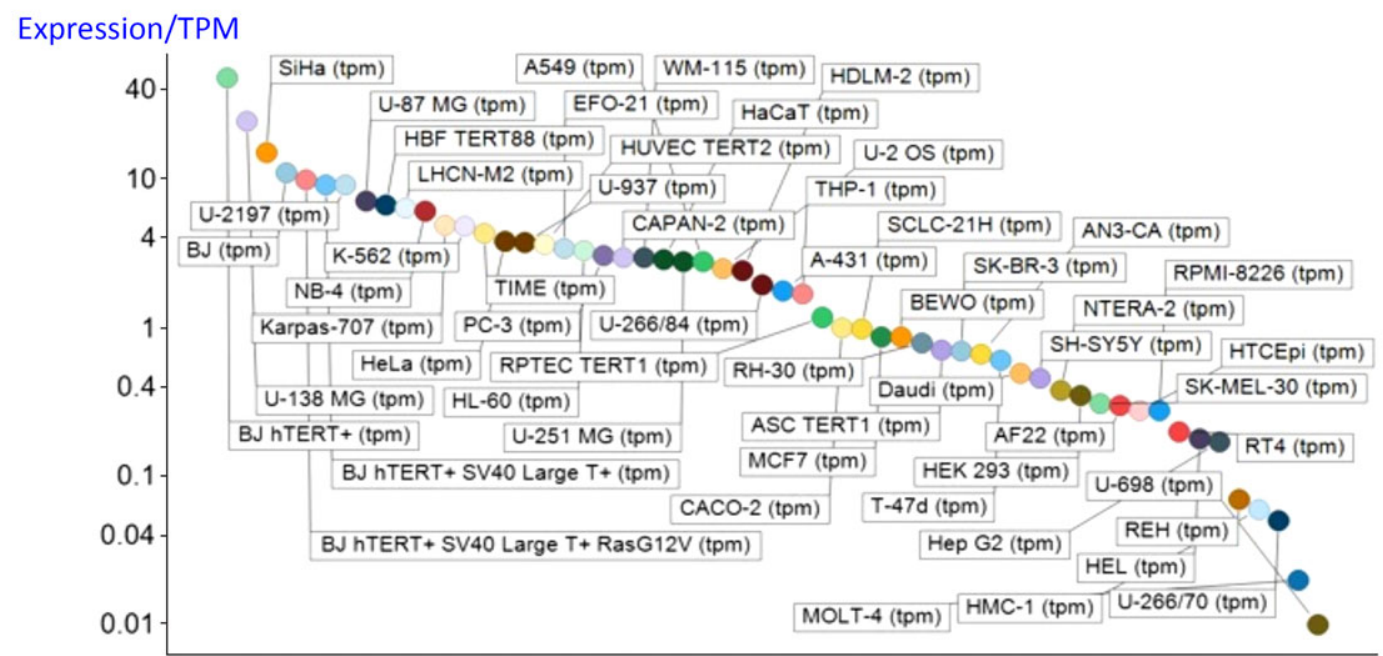

Different cell lines

Fig. 4. Differences in expression of SLC22A4 transcript in a series of mammalian cell lines. Data are from Thul et al. ${ }^{(186)}$ and O’Hagan et al. ${ }^{(119)}$. For a colour figure, see the online version of the paper.

take up exogenous natural products ${ }^{(203)}$. In the case of the cocaine transporter ${ }^{(204)}$, a simple narrative can serve to explain how a cocaine-mediated ability to outrun a predator such as a sabre-tooth tiger can rather obviously be selected provided the bioactive substance is actually taken up by the host. More generally, the ability to transport exogenous natural products is likely to be selected for when these confer fitness benefits on the host ${ }^{(205)}$, and this probably underpins the finding that successful, marketed drugs are indeed similar to (mainly 'secondary') natural products ${ }^{(203)}$.

\section{Oxidative stress}

Oxidative stress is widespread to the point of ubiquity in chronic, inflammatory diseases ${ }^{(206,207)}$, with over fifty papers having the words 'oxidative', 'stress' and 'review' in their titles at PubMed in 2018 alone! It can occur when oxygen tension is low and respiratory chains are over-reduced such that they reduce $\mathrm{O}_{2}$ with one electron to superoxide or two electrons to $\mathrm{H}_{2} \mathrm{O}_{2}$, instead of the four that are used during the reduction of dioxygen to water by cytochrome oxidase ${ }^{(208)}$ (Fig. 5). Peroxides are also produced in vivo by various oxidases and peroxidases, such as xanthine oxidase, by reduction of dioxygen (for example, Babior ${ }^{(209)}$, Cave et $a l .{ }^{(210)}$ and Bedard \& Krause $\left.{ }^{(211)}\right)$.

While $\mathrm{H}_{2} \mathrm{O}_{2}$ and superoxide are certainly capable of effecting unwanted oxidations, it is the hydroxyl radical that is the key. Thus an important reaction of $\mathrm{H}_{2} \mathrm{O}_{2}$ with (free or poorly liganded) $\mathrm{Fe}(\mathrm{II})$ is the Fenton reaction ${ }^{(208,212,213)}$, leading to the very reactive and damaging hydroxyl radical $\left(\mathrm{OH}^{*}\right)$ :

$$
\mathrm{Fe}(\mathrm{II})+\mathrm{H}_{2} \mathrm{O}_{2} \rightarrow \mathrm{Fe}(\mathrm{III})+\mathrm{OH}^{-}+\mathrm{OH}^{\bullet}
$$

which can react within nanoseconds with anything adjacent. The role of Fe is absolutely vital here ${ }^{(208,213)}$. Superoxide can also react with ferric Fe in the Haber-Weiss reaction ${ }^{(214-216)}$ to produce Fe(II) again, thereby effecting redox cycling, and meaning the 'iron' is catalytic (Fig. 6):

$$
\mathrm{O}_{2}^{\bullet-}+\mathrm{Fe}(\mathrm{III}) \rightarrow \mathrm{O}_{2}+\mathrm{Fe}(\mathrm{II})
$$

In addition $\mathrm{O}_{2}{ }^{-{ }^{-}}$can release 'catalytic' $\mathrm{Fe}$ from $\mathrm{Fe}-\mathrm{S}$ clusters in certain proteins and from ferritin ${ }^{(208,217)}$, another way in which it can promote the Fenton reaction. Note that other reactions can produce $\mathrm{OH}^{*}$ anaerobically ${ }^{(218)}$. Because $\mathrm{OH}^{*}$ is so reactive it is not really observable in its free form; its action is detected via products of molecules with which it has reacted. These include 8 -oxo-guanine derivatives ${ }^{(219)}$, nitrotyrosine ${ }^{(220-222)}$ (itself formed from peroxynitrite ${ }^{(223,224)}$, possibly formed more commonly via superoxide ${ }^{(225,226)}$ ), 4-hydroxy-nonenal ${ }^{(227)}$, and many others reviewed previously ${ }^{(208)}$. In evaluating the antioxidant potency of ERG or anything else, it is molecules such as these that are normally assessed. Although the literature is somewhat scattered and heterogeneous, it seems clear that as well as hydroxyl radicals ${ }^{(228-232)}$, ERG can also react with and detoxify, or prevent the formation of, singlet oxygen ${ }^{(233-242)}$, ozone ${ }^{(243)}$, superoxide ${ }^{(231,241,244-246)}$, peroxide $^{(32,124,247,248)}$, hypochlorite ${ }^{(32,232,249)}$ and peroxyni-

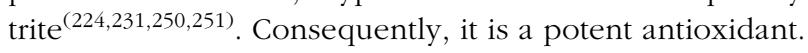




\section{Production of peroxide and superoxide in the respiratory chain}

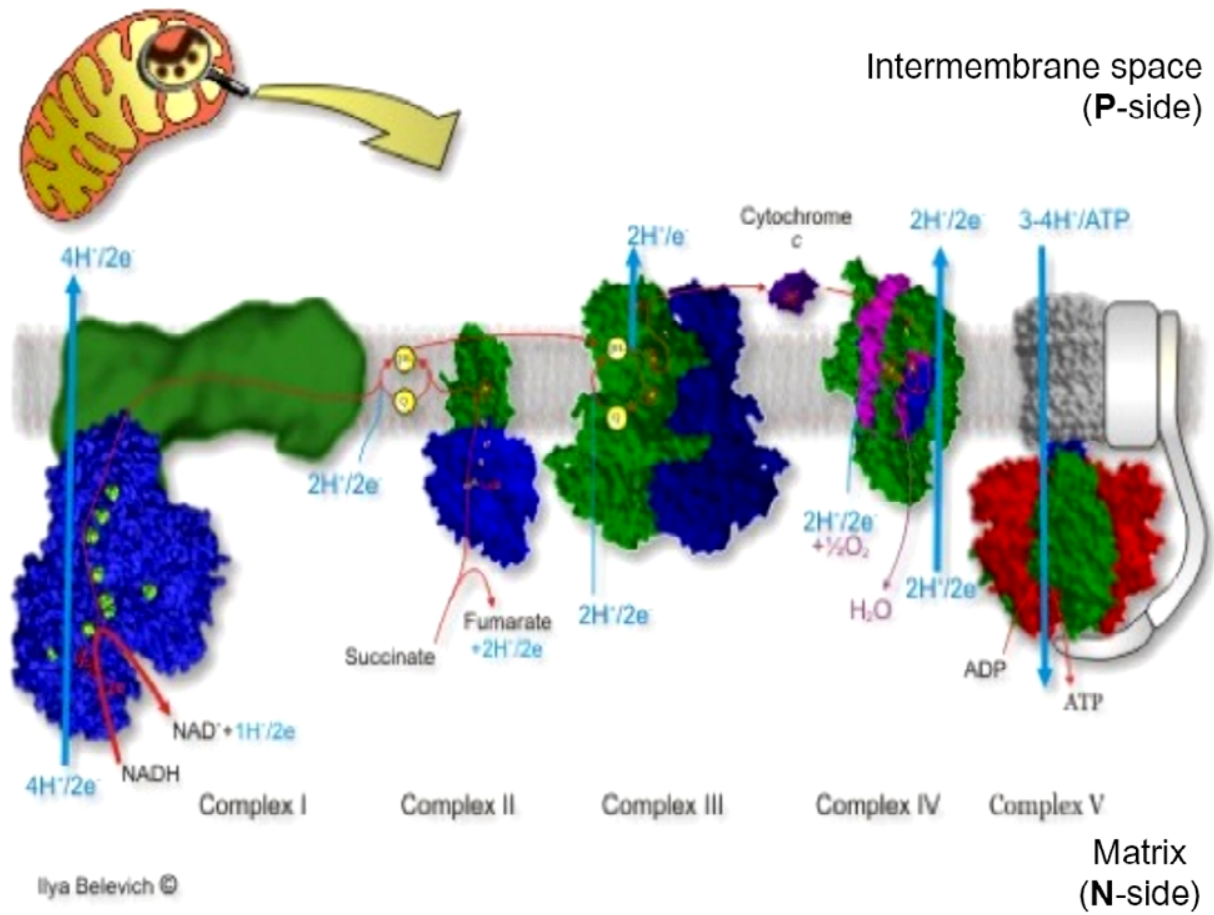

Original at http://www.biocenter.helsinki.fi/bi/biophys/biophys_research.html

Fig. 5. Superoxide and peroxide are produced by 1 - and 2-electron reduction of dioxygen by the mammalian respiratory chain. For a colour figure, see the online version of the paper.

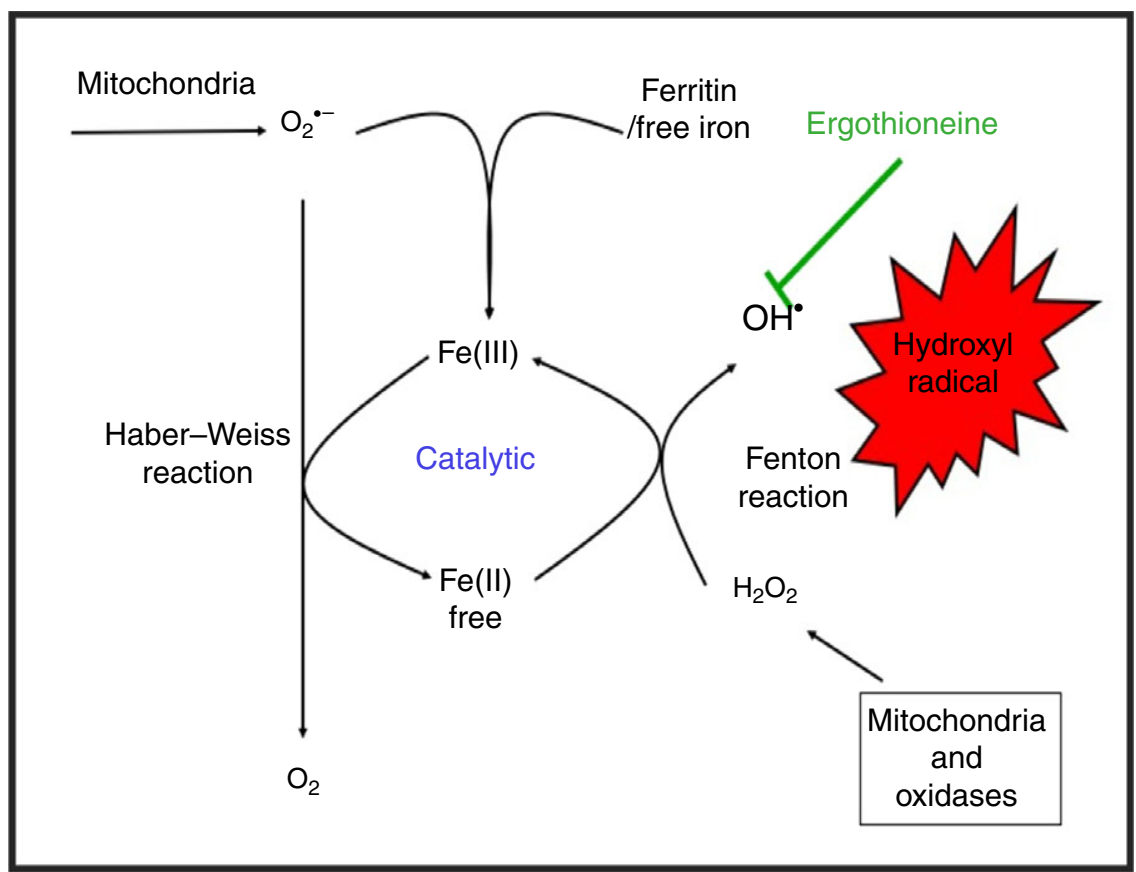

Fig. 6. Catalytic roles of unliganded iron in hydroxyl radical production via the Fenton and Haber-Weiss reactions. This can be stopped by ensuring that iron is fully liganded. For a colour figure, see the online version of the paper. 


\section{Roles in the producer}

Although it is not a priori certain that they would be the same in both producer and consumer organisms, it is of interest, before looking at higher organisms, to consider the roles of ERG in the producer organisms themselves. In the case of C. purpurea, the ERG serves as an antioxidant to neutralise a plant host defence response based on $\mathrm{H}_{2} \mathrm{O}_{2}$ that would otherwise inhibit the production of its conidia ${ }^{(252,253)}$. In $M$. tuberculosis and other mycobacteria ${ }^{(254)}$, and also in other actinobacteria $^{(255)}$ and in fungi ${ }^{(247,256,257)}$, it is clear that ERG can have a role as an antioxidant ${ }^{(66,258-260)}$ and also act as a buffer against reductive stress ${ }^{(261)}$. In nature many organisms can be subjected to oxidative stress, and produce a variety of molecules to combat it ${ }^{(262-270)}$. This also seems true of mushrooms ${ }^{(271,272)}$, where ERG is typically the main antioxidant ${ }^{(273-275)}$, and where it may also inhibit the oxidative enzyme tyrosinase ${ }^{(276)}$. Given suggestions that the "purpose' of secondary metabolite formation is to serve as a signalling molecule in different cells of the producer organism, i.e. as a pheromone ${ }^{(277)}$, it is interesting to note that this may also involve crosstalk of $\mathrm{ERG}^{(37)}$, due in part to the complex networks in which it may be embedded ${ }^{(278)}$. The same is true of the imidazole thiol-containing ovothiol ${ }^{(279,280)}$. In a similar vein, and although outwith our scope here, we note the potential of other antioxidant natural products such as curcumin ${ }^{(281-286)}$.

\section{Nutritional sources}

Betaines are generally seen as nutritionally beneficial ${ }^{(287)}$, and

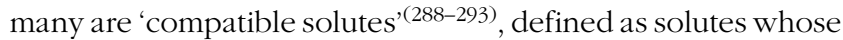
accumulation assists the survival of the organism when undergoing various kinds of stress such as osmotic or thermal stress. However, of these, only ERG is seen as a major antioxidant. Although a variety of foodstuffs such as oats ${ }^{(294,295)}$ contain ERG because they take it up from exogenous sources, it is really mushrooms that are the prime sources for humans ${ }^{(18,294)}$. Indeed, ERG has been proposed as a nutritional biomarker for mushroom consumption ${ }^{(296,297)}$, albeit that different mushrooms typically contain different amounts ${ }^{(275,298-300)}$, and these can vary with physiological or environmental conditions ${ }^{(301-305)}$. Those with the highest amounts include oyster mushrooms (Pleurotus spp., up to $4 \mathrm{mg} / \mathrm{g} \mathrm{DM})^{(306)}$, the golden oyster Pleurotus citrinopileatus with $10.65 \mathrm{mg} / \mathrm{g}$ $\mathrm{DM}^{(307,308)}$, and shiitake (Lentinula edodes, about $1 \mathrm{mg} / \mathrm{g}$ DM), while of those more common outside Asia, porcini or ceps (Boletus edulis, $>7 \mathrm{mg} / \mathrm{g}$ DM), stand out ${ }^{(6,294,300)}$. However, even common field or 'button' mushrooms, Agaricus bisporus, contain some $0.4 \mathrm{mg} / \mathrm{g} \mathrm{DM} \mathrm{DM}^{(275,299,300,309)}$. Note too that tempe(h), the result of a solid substrate Rbizopus oligosporus fermentation ${ }^{(310-314)}$, also contains high levels of $\mathrm{ERG}^{(6)}$. Mushrooms may also be a significant benefit to those seeking a meat-free diet as they can be made to share certain organoleptic features with meat ${ }^{(315,316)}$. Notably, the production of cultivated, edible mushrooms worldwide has increased more than 30-fold since 1978, whereas the population has only increased by about $1 \cdot 7$-fold during the same period ${ }^{\text {(10,317) }}$.
Some studies that have demonstrated nutritional/health benefits of mushrooms and their antioxidant activity ${ }^{(125,271,318-351)}$ ) did not always seek to deconstruct these into their constituents such as ERG, but ERG is clearly the chief mushroom antioxidant. We note too that some effects may be dependent on the composition of the gut microflora ${ }^{(352)}$, that are of course themselves likely to be changed by ERG, just as they are by many other non-antibiotic drugs ${ }^{(353)}$.

\section{Safety}

Producer organisms such as mushrooms are well known to make many secondary metabolites, some of which can be highly toxic $^{(354-356)}$ and by various mechanisms ${ }^{(357)}$. Notwithstanding the highly variable intake between individuals ${ }^{(358)}$, however, a number of high-dose studies have indicated that ERG is safe for mammalian consumption at levels far in excess of those likely to be encountered in foodstuffs ${ }^{(125,131,359,360)}$, and it has been declared safe by relevant committees such as those of the European Food Standards Agency ${ }^{(361,362)}$. It also lacks any detectable mutagenicity or genotoxicity in such assays, even at very high doses ${ }^{(363,364)}$.

\section{Analytics}

Leaving aside early efforts such as the colorimetric methods of Hunter ${ }^{(365)}$, of Melville and colleagues ${ }^{(76,85,366)}$ and of Carlsson et al. ${ }^{(367)}$, a variety of analytical methods have been proposed $^{(4)}$, mostly involving capillary electrophoresis $(368,369)$ or chromatography ${ }^{(368,370-372)}$ coupled to absorbance ${ }^{(373,374)}$, fluorescence detection ${ }^{(375-378)}$, electrochemical detection ${ }^{(379)}$ or $\mathrm{MS}^{(72,127,256,368,378,380-382)}$. A useful feature is that ERG is unusually stable, in that anhydrous ERG decomposes only at $275-276^{\circ} \mathrm{C}^{(76)}$, allowing its isolation at temperatures close to that of boiling water ${ }^{(72)}$. As judged by the reversibility of its acid-base titration ${ }^{(383)}$, it is also stable to extremes of $\mathrm{pH}$.

Industrial purification of glycine betaine is done by extraction with water ${ }^{(384)}$ and subsequent ion exchange chromatography ${ }^{(384,385)}$, which can be done in simulated moving bed fashion ${ }^{(386)}$. Glycine betaine can then be crystallised ${ }^{(384)}$. As glycine betaine is structurally similar to ERG, this straightforward industrial process could potentially be adapted for ERG.

\section{Serum and other concentrations}

While most ERG is inside erythrocytes in whole blood $^{(6,121,122,129,387)}$, there have been a number of measurements of ERG concentrations in serum. Unsurprisingly it varies with $\operatorname{diet}^{(388,389)}$, starvation ${ }^{(390)}$, age ${ }^{(391,392)}$ and other factors, including diseases of oxidative stress ${ }^{(393)}$, with typical values of $20-100 \mu \mathrm{g} / \mathrm{ml}$. A detailed list is provided by Cheah \& Halliwell ${ }^{(4)}$; a smaller listing is given in Table 3. Interestingly, ERG is also present in seminal fluid ${ }^{(394-396)}$ and human breast milk $^{(6)}$. Any possible correlation with male fertility ${ }^{(397)}$ seems not to have been established, though there were no negative effects $^{(398)}$, and ERG improved oocyte quality and maturation 
Table 3. Concentrations of ergothioneine in human serum

\begin{tabular}{|c|c|c|c|}
\hline & Concentration & & Study \\
\hline Crohn's disease & $7 \mu \mathrm{g} / \mathrm{ml}$ & & (401) \\
\hline Healthy volunteer & $38 \mu \mathrm{g} / \mathrm{ml}$ & & (401) \\
\hline Healthy $1-10$ years & $15-20 \mu \mathrm{g} / \mathrm{ml}$ & & (387) \\
\hline Healthy $11-18$ years & $37 \mu \mathrm{g} / \mathrm{ml}$ & & (387) \\
\hline Healthy $19-50$ years & $23-30 \mu \mathrm{g} / \mathrm{ml}$ & & (387) \\
\hline $\begin{array}{l}\text { Healthy middle-aged } \\
\text { and older }\end{array}$ & $\begin{array}{l}\text { Median } 1 \mu \mathrm{M}=229 \mathrm{ng} / \mathrm{ml}, \\
\quad \text { range } 0.36-3.08 \mu \mathrm{M}^{*}\end{array}$ & $\begin{array}{l}\text { Inverse } \\
\text { correlation } \\
\text { with age }\end{array}$ & (571) \\
\hline Mice on normal diet & $58 \mu \mathrm{g} / \mathrm{ml}$ & & (131) \\
\hline
\end{tabular}

* Molecular weight $=229 \cdot 3$, so $1 \mathrm{~mm}=229 \mathrm{mg} / \mathrm{l}$.

in cows and sheep ${ }^{(399)}$. ERG is also present in eye lens, where its concentration is lower in individuals with cataracts ${ }^{(400)}$.

\section{Metabolism and excretion}

ERG is metabolised and excreted only slowly ${ }^{(360,371,401,402)}$. In a recent and detailed study, Cheah et al. ${ }^{(360)}$ administered $5-25 \mathrm{mg}$ daily doses of ERG to human volunteers for $7 \mathrm{~d}$. There was little urinary excretion $(<4 \%)$, and the main metabolites were hercynine, plus lesser amounts of $S$-methyl-ERG, whose concentrations were well correlated with the level of ERG and the dose of ERG given. Similar observations were made in mice ${ }^{(131)}$. Various other biomarkers of oxidative stress (for example, 8 -iso-PGF2 $\alpha$ from lipid peroxidation) were lowered concomitantly in the human study, attesting to the antioxidant functions of ERG in vivo, although in this case the healthy young subjects were probably not suffering from oxidative stress. There was also quite some variation in uptake between individuals, presumably reflecting variation in their expression of SLC22A4. Agrobacterium radiobacter ${ }^{(403)}$ and other bacteria ${ }^{(404-409)}$ contain an ergothionase that degrades ERG to thiolurocanic acid (3-(1H-imidazol-5-yl)prop-2-enethioic S-acid) and trimethylamine, also implying that such cells possess one or more transporters for ERG. The thiolurocanic acid can be further degraded to glutamate ${ }^{(410)}$.

Apparent fitness benefits and bioactivities of ERG and the role of SLC22A4

Given the great technical difficulties associated, because of its ubiquity, with withholding ergothoneine from a human or animal diet, one means of 'removing' ERG from a host is to remove the ERG transporter by genetic means. This has in fact been done in mice ${ }^{(401)}$; such SCL22A $4^{-/-}$mice had immeasurably low levels of ERG relative to controls, and were much more sensitive to oxidative stress than were the wild type. Similar effects were observed in Caenorhabditis elegans ${ }^{(411)}$. Polymorphisms in SLC22A4, of which there can be many ${ }^{(177,412-415)}$, under selection $^{(416)}$, have also been associated with ischaemic stroke $^{(417)}$, erythroid differentiation ${ }^{(418)}$, hearing loss ${ }^{(412)}$, rheumatoid arthritis ${ }^{(126,180,419-427)}$, lupus ${ }^{(428)}$, Crohn's disease $^{(401,429-436)}$, hearing loss ${ }^{(412)}$, type 1 diabetes $^{(437)}$ and diabetic embryopathy ${ }^{(438)}$. The expression of SLC22A4 can itself be modulated by other factors, including by PPAR- $\alpha$ $\operatorname{activity}^{(439)}$. The very diversity of these diseases speaks naturally to a broad and common underlying cause, the easiest of which involves mechanisms of oxidative stress, inflammation and cell death.

\section{Mechanisms of action}

It has become common to discover a binding of a small molecule to another molecule such as a protein, and assume that this interaction, leading to activation or inhibition of the target, constitutes 'the' mechanism of action of the small molecule at a physiological level. Unfortunately this is rarely the case, and known drugs, despite often being selected for inhibiting potently a specific molecular target ${ }^{(147)}$, have, on average, six known binding targets $^{(440)}$. When these interactions ramify through a complex and non-linear biochemical network it can be hard to apportion the effects of a small exogenous molecule between the various interactions ${ }^{(441-443)}$.

A standard view of systems or network biology (for example, Kell $^{(444)}$ and Kell \& Knowles ${ }^{(445)}$ ) develops these ideas in four stages. In stages 1 and 2 we simply recognise the actors and the interactions between them at a qualitative level. Stages 3 and 4 then seek to describe the equations reflecting individual steps and the values of the parameters of those equations. Armed with these we can make an ordinary or, if spatial resolution within a compartment is required, a partial differential equation model of the system. This can then be run and the sensitivities of each step determined ${ }^{(446-448)}$. We are very far from this last part, and so studies of the effects of ERG have in general $^{(449)}$ been rather descriptive in nature. Many have been at the level of processes rather than mechanisms, and they have been reviewed in detail ${ }^{(3,360)}$. Table 4 and Fig. 7 provide a selection of determinands that have been shown to change their concentrations or activities when ERG is added to the system of interest. In many cases it is not at all clear what the proximate mechanisms are. Note as just one example that the highly promiscuous transcription factor NF- $\mathrm{B}^{(450-452)}$, whose frequencydependent activity directly affects the expression of hundreds of enzymes ${ }^{(453,454)}$, is itself redox-sensitive ${ }^{(455-458)}$, and is affected by $\mathrm{ERG}^{(459,460)}$, while NF- $\mathrm{KB}$ increases the rates of SC22A4 transcription ${ }^{(419)}$. Thus, deconstructing the many possible direct and consequential interactions of ERG with proteins, $v$. whether these are simply a consequence of its provision of a more reducing environment, is likely to be a formidable task. In a similar vein, the effects of ERG on the microbiomes of the hosts are likely to be significant, but do not yet seem to have been studied.

It seems clear that the chief role of ERG, via a variety of mechanisms, including directly, is to serve as an antioxidant and cellular protectant against various kinds of reactive oxygen and $\mathrm{N}$ species.

\section{Cytoprotection}

At a high level, ERG is seen as an excellent cytoprotectant against all kinds of cellular insults ${ }^{(3,4,6,124)}$. We split some of the more detailed analyses into subdivisions in the following few sections. 
Table 4. Biological properties whose expression or activity varies on exposure of a biological system to ergothioneine (ERG) or a modulation of SLC22A4 activity

\begin{tabular}{|c|c|c|c|}
\hline Determinand & System & Comments & $\begin{array}{l}\text { Selected } \\
\text { reference(s) }\end{array}$ \\
\hline $\begin{array}{l}\text { Cataract formation induced by } \\
\text { glucocorticoid }\end{array}$ & Developing chick embryo & ERG inhibits & (572) \\
\hline \multirow[t]{2}{*}{ Cell death } & $\begin{array}{l}\text { Human neuronal hybridoma cell line } \\
\mathrm{N}-18-\mathrm{RE}-105\end{array}$ & $\mathrm{H}_{2} \mathrm{O}_{2}$ challenge & (251) \\
\hline & Caenorhabditis elegans & Protection from amyloid- $\beta$-induced cell death & (521) \\
\hline Cell injury & Rat pheochromocytoma cells & Methylglyoxal challenge & (573) \\
\hline \multirow[t]{2}{*}{ Cell proliferation } & K562 cells & Involvement of SLC22A4 & (418) \\
\hline & Caco-2 cells & Involvement of SLC22A4 & (429) \\
\hline Diabetic embryopathy & Rats & ERG reduced it to control levels & (574) \\
\hline DNA damage in mitochondria & HeLa, RAW 264.7, HaCaT, PC12 cells & siRNA knockdown of SLC22A4 & (3) \\
\hline Embryo development & Sheep & Improvement, despite non-uptake of ERG & $(399,575)$ \\
\hline Embryo quality and maturation & Cows & Improvement & $(576)$ \\
\hline $\begin{array}{l}\text { Excitotoxicity caused by } \mathrm{N} \text {-methyl-D- } \\
\text { aspartate }\end{array}$ & Rat & Protection by ERG & (577) \\
\hline Glycolysis & Erythrocytes & $\begin{array}{l}\text { Preservation of lactate production during } \\
\text { starvation }\end{array}$ & (578) \\
\hline Hepatocyte injury induced by $\mathrm{CCl}_{4}$ & Hepatocytes & Protection, also by $\beta$-hydroxy derivative & (579) \\
\hline Immune modulation & Mouse macrophages & Skewing towards a Th17 response & (580) \\
\hline Immunotherapy & Tumour cells & $\begin{array}{l}\text { Improved vaccine responses by dampening } \\
\text { cytotoxic T-lymphocyte suppression }\end{array}$ & (581) \\
\hline IL-8 & Alveolar macrophages & $\begin{array}{l}\mathrm{H}_{2} \mathrm{O}_{2} \text { and TNF- } \alpha \text { induction. Possible } \\
\text { intermediacy of NF- } \mathrm{kB}\end{array}$ & (460) \\
\hline Fe incorporation into protoporphyrin & Erythrocyte fractions & $\begin{array}{l}\text { Said to keep Fe reduced; does not seem to } \\
\text { have been confirmed }\end{array}$ & (562) \\
\hline Kidney fibrosis & Mice & $\begin{array}{l}\text { Worsens during chronic kidney disease if } \\
\text { SLC22A4 removed }\end{array}$ & (582) \\
\hline \multirow[t]{2}{*}{ Lipid peroxidation } & HeLa, RAW 264.7, HaCaT, PC12 cells & siRNA knockdown of SLC22A4 & (3) \\
\hline & In vitro & Free radical initiated with anthracyclines & (583) \\
\hline Lung injury & Rats & $\begin{array}{l}\text { Cytokine treatment; damage prevented by } \\
\text { ERG }\end{array}$ & (505) \\
\hline Memory & C57BL/6J mice & $\begin{array}{l}\text { Attenuates memory loss induced by } \\
\text { D-galactose; synergistic with melatonin }\end{array}$ & (584) \\
\hline \multirow[t]{7}{*}{ Metal ion chelation } & $\mathrm{Co}^{++}, \mathrm{Cu}^{++}, \mathrm{Ni}^{++}, \mathrm{Zn}^{++}$ & Direct and within enzymes & (527) \\
\hline & $\mathrm{Cu}^{++}>\mathrm{Hg}^{++}>\mathrm{Zn}^{++}>$ & IR measurements & (585) \\
\hline & $\mathrm{Cd}^{++}>\mathrm{Co}^{++}>\mathrm{Zn}^{++}$ & & \\
\hline & $\mathrm{Cu}^{++}$ & NMR & (586) \\
\hline & $\mathrm{Cu}^{++}$ & Chelation prevents DNA damage & (473) \\
\hline & $\mathrm{Cu}^{++}$ & Chelation prevents DNA damage & (472) \\
\hline & $\mathrm{Hg}^{++}$ & In intact erythrocytes, after glutathione & (587) \\
\hline Mutagenesis protection & Multiple & Often involving singlet oxygen & $(588-591)$ \\
\hline Neuronal differentiation & Neural progenitor cells & ERG stimulated differentiation & (592) \\
\hline $\mathrm{NF}-\kappa \mathrm{B}$ & MH7A cells & Affects SLC22A4 expression & (419) \\
\hline Nrf2 & HaCaT skin cells & Anti-apoptotic following UV irradiation & (549) \\
\hline$S$-nitrosoglutathione catabolism & In vitro & ERG stimulates & (593) \\
\hline S6K1 mTOR and neurotrophin 4/5-TrkB & Neural stem cells & Rapid induction after ERG exposure & (594) \\
\hline Sickle cell anaemia & & ERG is protective & (595) \\
\hline SIRT1 and SIRT6 & Endothelial cells & Protection $v$. glucose-induced senescence & (482) \\
\hline Sperm motility & Boars & Protection $v$. $\mathrm{Cu}^{++}$inhibition & (596) \\
\hline
\end{tabular}

siRNA, small interfering RNA; mTOR, mammalian target of rapamycin; SIRT, sirtuin.

\section{Oxidative stress}

Oxidative stress can be defined and measured in many ways $^{(461-468)}$, but is broadly taken to involve a dysregulation in the various redox systems of the organism of interest, coupled to the production of various 'reactive oxygen species', principally peroxide, superoxide, hydroxyl radical, and singlet oxygen. ERG has been shown to decrease oxidative stress in the liver and kidney of rats ${ }^{(469)}$, rescued cells from $\beta$-amyloid-induced apoptotic death ${ }^{(231)}$, protected against palmitic acid-induced cell death ${ }^{(470)}$, mercuric chloride-induced cellular dysfunction $^{(471)}$, and prevented $\mathrm{Cu}$-induced oxidative damage to $\mathrm{DNA}^{(472,473)}$. It is protective against the oxidation of various kinds of molecule $\mathrm{e}^{(251,474)}$, including $\operatorname{astaxanthin}^{(475)}$, and accumulates in a guinea-pig model of non-alcoholic fatty liver disease ${ }^{(476)}$, massively so in mouse models of myocardial infarction and heart failure ${ }^{(477)}$, and in a rat model of optic nerve crush $^{(478)}$. It serves to resist $\mathrm{H}_{2} \mathrm{O}_{2}$-induced cell death ${ }^{(479)}$, pyrogallolinduced toxicity ${ }^{(124)}$, cisplatin- ${ }^{(480)}$ or oxaliplatin-induced ${ }^{(481)}$ toxicity, glucose-induced senescence ${ }^{(246,482)}$, as well as lipopolysaccharide-induced inflammation ${ }^{(483)}$. In particular, it is protective against ischaemia-reperfusion injury ${ }^{(484-486)}$, and may have uses in prolonging the lifetime of stored blood $^{(487)}$. Probably such antioxidant activities are at the core of its biological benefits. 


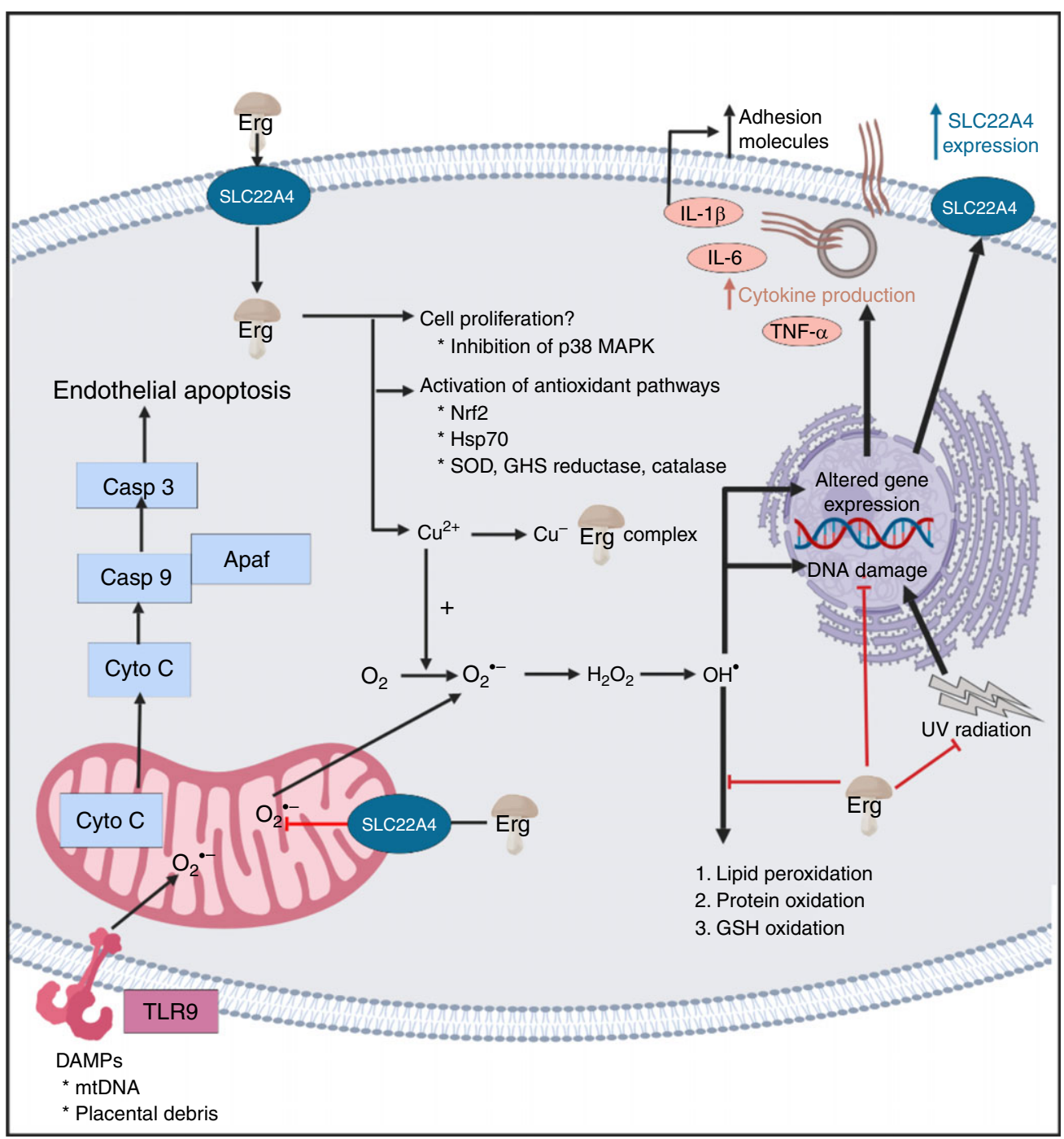

Fig. 7. Overview of some of the effects of ergothioneine in mammalian systems. For a colour figure, see the online version of the paper.

Ergothioneine as a therapeutic for chronic inflammatory diseases?

Inflammation and oxidative stress go hand in hand ${ }^{(3)}$, since reactive oxygen species (and materials such as bacterial cell wall components that can lead to their generation ${ }^{(206,488)}$, lead to the production of inflammatory cytokines. Although a great many chronic, inflammatory diseases are recognised as having an oxidative stress component ${ }^{(223)}$, the history of treating them with antioxidants such as ascorbate has largely been a litany of failure, with the treatment arm often even giving worse prognoses than the placebo ${ }^{(6,223,489-501)}$. Arguably this is because nominally antioxidant molecules such as ascorbate have complex, multi-electron redox chemistry, and can in fact act as pro-oxidants ${ }^{(502,503)}$, especially in the presence of free $\mathrm{Fe}^{(208,213)}$ or $\mathrm{Cu}^{(504)}$. This is not an issue with ERG, however, partly because it can chelate them, and ERG levels are decreased, or ERG has been proposed as a useful antioxidant, in diseases such as acute respiratory distress syndrome ${ }^{(505)}$, CVD $^{(506,507)}$, chronic obstructive pulmonary disease ${ }^{(223)}$, preeclampsia ${ }^{(8)}$ (see also Turner et al. ${ }^{(128)}$ ), overhydrated hereditary stomatocytosis ${ }^{(508)}$, and is significantly lowered in others such as certain leukaemias ${ }^{(121,122)}$. The evidence for this comes from a variety of sources, including metabolite measurements in human subjects ${ }^{(121,122,509)}$, and intervention studies in both animals $^{(505)}$ and cell lines ${ }^{(3,124,506)}$. In particular, there is a notable relationship between ERG consumption and longevity (Fig. 6 in Beelman et al. ${ }^{(10)}$ ), while in a 3236-participant Swedish study, ERG was the metabolite most strongly connected to a 'health conscious food pattern' and was associated with a lower risk of coronary disease (hazard ratio (HR) per 1 SD increment of ERG, $\mathrm{HR}=0.85 ; P=0.01$ ), cardiovascular mortality (HR $=0.79 ; \quad P=0.002)$ and overall mortality $\left(\mathrm{HR}=0.86 ; P=4 \times 10^{-5}\right)^{(509)}$.

\section{Neurological diseases and cognitive function}

Mushrooms have been shown to have very substantial effects on cognitive function ${ }^{(341,348,510-513)}$, and this is mainly ascribed to their ERG content, that also deceases with the age of the consumer ${ }^{(391)}$. The kinds of evidence include both doubleblind, placebo-controlled clinical trials ${ }^{(341)}$ and observational 
(cross-sectional) studies in both humans ${ }^{(348,510-512)}$ and rodents ${ }^{(513)}$. Thus, consuming 1.5 mushroom servings per week was associated with a halving of the incidence of mild cognitive impairment (a precursor of Alzheimer's dementia), while intake of nine servings per week was associated with a five-fold decrease ${ }^{(348)}$. Note, however, that at least one mushroom trial indicated no measurable benefits in healthy young physical education students ${ }^{(514)}$. Brain and serum ERG levels are also markedly different in Parkinson's disease ${ }^{(515)}$, reviewed in Hang et al. ${ }^{(516)}$, Shao \& Le ${ }^{(517)}$ and Shah \& Duda ${ }^{(518)}$, and even in sudden infant death syndrome ${ }^{(519)}$, and ERG has been shown to be protective against $\beta$-amyloid-induced neuronal injury ${ }^{(520)}$ and cytotoxicity ${ }^{(521)}$. It can also act as an antidepressant ${ }^{(522)}$. The evidence for this comes from direct studies ${ }^{(520)}$ and feeding experiments ${ }^{(522)}$ in mice, as well as via the reduction of $\beta$-amyloid peptide in a transgenic $C$. elegans model ${ }^{(521)}$. As mentioned above, SLC22A4 polymorphisms are associated with ischaemic stroke $e^{(417)}$.

\section{Use of ergothioneine as an antioxidant in processed foodstuffs}

Just as living beings exploit antioxidants, most foodstuffs can also be oxidised to produce taints, rancidity or other undesirable products $^{(523-525)}$, often via the Fenton reaction ${ }^{(208,526)}$. ERG inhibits polyphenoloxidases ${ }^{(527)}$, and thus ERG has been used in the feed of the shrimp Marsupenaeus japonicas to prevent melanosis during storage ${ }^{(528)}$, while ERG-rich mushroom extract has also been used to prevent melanosis in post-harvest storage of the crab Chionoecetes japonicus ${ }^{(529)}$. Thus, one can also envisage a role for ERG, whether natural or added, in extending shelf lives and commercial value $\mathrm{e}^{(245,328,475,528-539)}$. The thermostability of ERG is of particular importance here.

\section{Use of ergothioneine in cosmetics}

Just as processed foodstuffs 'age', so do tissues such as the skin, and although the same principles apply ${ }^{(540)}$, it is common to refer to nutraceuticals that are also aimed at having cosmetic benefits as 'cosmeceuticals'(541-543). Here too, ERG has been widely used $^{(543-547)}$, since much skin damage is caused by UV-mediated reactive oxygen species production ${ }^{(548)}$; indeed, ERG is known as a skin protectant ${ }^{(240-244,549-551)}$.

\section{Role of ergothioneine as a cofactor?}

Although it is possible that the role of ERG lies simply in being an antioxidant capable of mopping up hydroxyl radicals and other reactive oxygen species, especially in prokaryotes $^{(36,66,93,254,255,258-260,552,553)}$, the roles of most other vitamins involve interaction with proteins, often as cofactors. This is also true for mycothiol ${ }^{(73,554-556)}$, though that molecule can also serve as a signal and nutrient resource ${ }^{(557)}$. However, despite many hypotheses ${ }^{(558,559)}$, the only example of ERG acting as a cofactor known to date is an involvement in the biosynthesis of lincomycin ${ }^{(560,561)}$. An early paper ${ }^{(562)}$ implying an involvement of ERG in the maintenance of a reduced state of
Fe in $\mathrm{Hb}$, although apparently accurate, does not seem to have been followed up to date.

\section{Conclusions}

There is increasing awareness that health may be enhanced via the consumption of substances that either have no recommended daily intake or are taken at levels greater than normal, and such substances are commonly referred to as nutraceuticals. ERG, a potent and effective antioxidant, seems to be an important nutraceutical, and we rehearse a very broad literature, involving a great many cells, tissues and organisms, to that effect. The chief source of ERG in the human diet is mushrooms (usually the fruiting bodies of Basidiomycetes). The fact that a specific transporter known as SLC22A4 has evolved and been selected to effect ERG uptake in all known animals suggests strongly that ERG is of benefit to its consumers. While the evidence that ERG may be a useful nutraceutical as a preventive or palliative for various inflammatory diseases is extensive, it is mostly circumstantial rather than definitive, though many examples exist of the benefits of mushrooms in combating the results of oxidative stress.

Without mechanisms, finding that the concentration of a dietary metabolite $\mathrm{X}$ is low in disease $\mathrm{Y}$ does not mean that giving it might be of benefit in the prevention, delay or cure of that disease, although cases can clearly be made when $\mathrm{X}$ is a vitamin, or oxidative stress is known to be a damaging component of $\mathrm{Y}^{(8,348)}$. Thus far, we lack examples in which ERG is found both to be low in individuals with a particular syndrome and where exogenous administration effects functional improvements, although - as reviewed above - we often have one or the other.

To assess definitively any health benefits of ERG, the 'gold standard' of randomised controlled trials may take time and money, but - as with mushrooms ${ }^{(335,563)}$ - are beginning. One trial with pure ERG has been registered ${ }^{(564)}$.

\section{Note added in proof}

A recent paper indicates that ERG relieves the effects seen in a rat model of the pregnancy disorder pre-eclampsia ${ }^{(597)}$.

\section{Acknowledgements}

We thank the Biotechnology and Biological Sciences Research Council (BBSRC) (grants no. BB/R000093/1 and no. BB/ P009042/1) and the Novo Nordisk Foundation (grant no. NNF10CC1016517) for financial support.

D. B. K. decided to bring together the multifaceted contributions of the various authors listed. Their previous contributions to ergothioneine and antioxidant biology may be seen in the references cited. All authors contributed to and approved the final manuscript.

I. B., S. A. v. d. H. and D. B. K. are named inventors on a patent application involving the biotechnological production of $\mathrm{L}-(+)-$ ergothioneine in yeast. For the other authors, there are no conflicts of interest. 


\section{References}

1. Kraemer K, Semba RD, Eggersdorfer M, et al. (2012) Introduction: the diverse and essential biological functions of vitamins. Ann Nutr Metab 61, 185-191.

2. Semba RD (2012) The discovery of the vitamins. Int J Vitam Nutr Res 82, 310-315.

3. Paul BD \& Snyder SH (2010) The unusual amino acid L-ergothioneine is a physiologic cytoprotectant. Cell Death Differ 17, 1134-1140.

4. Cheah IK \& Halliwell B (2012) Ergothioneine; antioxidant potential, physiological function and role in disease. Biochim Biophys Acta 1822, 784-793.

5. Halliwell B, Cheah IK \& Drum CL (2016) Ergothioneine, an adaptive antioxidant for the protection of injured tissues? A hypothesis. Biochem Biophys Res Commun 470, 245-250.

6. Halliwell B, Cheah IK \& Tang RMY (2018) Ergothioneine - a diet-derived antioxidant with therapeutic potential. FEBS Lett 592, 3357-3366.

7. Ames BN (2018) Prolonging healthy aging: longevity vitamins and proteins. Proc Natl Acad Sci U S A 115, 10836-10844.

8. Kerley RN, McCarthy C, Kell DB, et al. (2018) The potential therapeutic effects of ergothioneine in pre-eclampsia. Free Radic Biol Med 117, 145-157.

9. Anonymous (2015) L-Ergothioneine. http://www.tetrahedron. fr/products/research/l-ergothioneine (accessed August 2019).

10. Beelman RB, Kalaras MD, John P, et al. (2019) Micronutrients and bioactive compounds in mushrooms: a recipe for healthy aging? Nutr Today 54, 16-22.

11. Cencic A \& Chingwaru W (2010) The role of functional foods, nutraceuticals, and food supplements in intestinal health. Nutrients 2, 611-625.

12. Bahadoran Z, Mirmiran P \& Azizi F (2013) Dietary polyphenols as potential nutraceuticals in management of diabetes: a review. J Diabetes Metab Disord 12, 43.

13. Ogle WO, Speisman RB \& Ormerod BK (2013) Potential of treating age-related depression and cognitive decline with nutraceutical approaches: a mini-review. Gerontology 59, 23-31.

14. Ragle RL \& Sawitzke AD (2012) Nutraceuticals in the management of osteoarthritis: a critical review. Drugs Aging 29, 717-731.

15. Chauhan B, Kumar G, Kalam N, et al. (2013) Current concepts and prospects of herbal nutraceutical: A review. J Adv Pharm Technol Res 4, 4-8.

16. Borghi C \& Cicero AF (2017) Nutraceuticals with a clinically detectable blood pressure-lowering effect: a review of available randomized clinical trials and their meta-analyses. Br J Clin Pharmacol 83, 163-171.

17. Aruoma OI, Coles LS, Landes B, et al. (2012) Functional benefits of ergothioneine and fruit- and vegetable-derived nutraceuticals: overview of the supplemental issue contents. Prev Med 54, Suppl., S4-S8.

18. Rathore H, Prasad S \& Sharma S (2017) Mushroom nutraceuticals for improved nutrition and better human health: a review. PharmaNutrition 5, 35-46.

19. Espín JC, García-Conesa MT \& Tomás-Barberán FA (2007) Nutraceuticals: facts and fiction. Phytochemistry 68, 29863008.

20. Sharif MK \& Khalid R (2018) Nutraceuticals: myths versus realities. In Therapeutic Foods, vol. 8, pp. 3-21 [AM Holban and AM Grumezescu, editors]. Cambridge, MA: Academy Press.

21. Singh S, Razak MA, Sangam SR, et al. (2018) The impact of functional food and nutraceuticals in health. In Therapeutic Foods, vol. 8, pp. 23-47 [AM Holban and AM Grumezescu, editors]. Cambridge, MA: Academy Press.
22. Spindler SR, Mote PL \& Flegal JM (2014) Lifespan effects of simple and complex nutraceutical combinations fed isocalorically to mice. Age (Dordr) 36, 705-718.

23. Poddar K, Kolge S, Bezman L, et al. (2011) Nutraceutical supplements for weight loss: a systematic review. Nutr Clin Pract 26, 539-552.

24. Camfield DA, Sarris J \& Berk M (2011) Nutraceuticals in the treatment of obsessive compulsive disorder (OCD): a review of mechanistic and clinical evidence. Prog Neuropsychopharmacol Biol Psychiatry 35, 887-895.

25. Goggs R, Vaughan-Thomas A, Clegg PD, et al. (2005) Nutraceutical therapies for degenerative joint diseases: a critical review. Crit Rev Food Sci Nutr 45, 145-164.

26. Naveen J \& Baskaran V (2018) Antidiabetic plant-derived nutraceuticals: a critical review. Eur J Nutr 57, 1275-1299.

27. Orr SL \& Venkateswaran S (2014) Nutraceuticals in the prophylaxis of pediatric migraine: evidence-based review and recommendations. Cephalalgia 34, 568-583.

28. Orr SL (2016) Diet and nutraceutical interventions for headache management: a review of the evidence. Cephalalgia 36, 1112-1133.

29. Tanret C (1909) A new base taken from rye ergot, ergothioneine. Ann Chim Phys 18, 114-124.

30. Tanret C (1909) The new base drawn from rye ergot, ergothioneine. Cr Hebd Acad Sci 149, 222-224.

31. Barger G \& Ewins AJ (1911) The constitution of ergothioneine: a betaine related to histidine. J Chem Soc 99, 2336-2341.

32. Servillo L, Castaldo D, Casale R, et al. (2015) An uncommon redox behavior sheds light on the cellular antioxidant properties of ergothioneine. Free Radic Biol Med 79, 228-236.

33. Franzoni F, Colognato R, Galetta F, et al. (2006) An in vitro study on the free radical scavenging capacity of ergothioneine: comparison with reduced glutathione, uric acid and trolox. Biomed Pharmacother 60, 453-457.

34. Hand CE, Taylor NJ \& Honek JF (2005) Ab initio studies of the properties of intracellular thiols ergothioneine and ovothiol. Bioorg Med Chem Lett 15, 1357-1360.

35. Hand CE \& Honek JF (2005) Biological chemistry of naturally occurring thiols of microbial and marine origin. J Nat Prod 68 , 293-308.

36. Fahey RC (2013) Glutathione analogs in prokaryotes. Biochim Biophys Acta 1830, 3182-3198.

37. Sheridan KJ, Dolan SK \& Doyle S (2015) Endogenous crosstalk of fungal metabolites. Front Microbiol 5, 732.

38. Fahey RC (2001) Novel thiols of prokaryotes. Annu Rev Microbiol 55, 333-356.

39. Jacob C (2006) A scent of therapy: pharmacological implications of natural products containing redox-active sulfur atoms. Nat Prod Rep 23, 851-863.

40. Clark WM (1960) Oxidation-reduction Potentials of Organic Systems. Baltimore, MD: The Williams and Wilkins Co.

41. Walz D (1979) Thermodynamics of oxidation-reduction reactions and its application to bioenergetics. Biochim Biophys Acta 505, 279-353.

42. Reyes AM, Pedre B, De Armas MI, et al. (2018) Chemistry and redox biology of mycothiol. Antioxid Redox Signal 28, 487-504.

43. Sharma SV, Van Laer K, Messens J, et al. (2016) Thiol redox and $\mathrm{pK}_{\mathrm{a}}$ properties of mycothiol, the predominant lowmolecular-weight thiol cofactor in the actinomycetes. Chembiochemistry 17, 1689-1692.

44. Kell DB \& Morris JG (1979) Oxidation-reduction properties of coenzyme M (2-mercaptoethane sulphonate) at the mercury electrode. FEBS Lett 108, 481-484. 
45. Achouba A, Dumas P, Ouellet N, et al. (2019) Selenoneine is a major selenium species in beluga skin and red blood cells of Inuit from Nunavik. Chemosphere 229, 549-558.

46. Little M, Achouba A, Dumas P, et al. (2019) Determinants of selenoneine concentration in red blood cells of Inuit from Nunavik (Northern Quebec, Canada). Environ Int 127, 243-252.

47. Turrini NG, Kroepfl N, Jensen KB, et al. (2018) Biosynthesis and isolation of selenoneine from genetically modified fission yeast. Metallomics 10, 1532-1538.

48. Rohn I, Kroepfl N, Bornhorst J, et al. (2019) Side-directed transfer and presystemic metabolism of selenoneine in a human intestinal barrier model. Mol Nutr Food Res 63, e1900080.

49. Klein M, Ouerdane L, Bueno M, et al. (2011) Identification in human urine and blood of a novel selenium metabolite, Semethylselenoneine, a potential biomarker of metabolization in mammals of the naturally occurring selenoneine, by HPLC coupled to electrospray hybrid linear ion trap-orbital ion trap MS. Metallomics 3, 513-520.

50. Pluskal T, Ueno M \& Yanagida M (2014) Genetic and metabolomic dissection of the ergothioneine and selenoneine biosynthetic pathway in the fission yeast, $S$. pombe, and construction of an overproduction system. PLOS ONE 9 , e97774.

51. Yamashita Y \& Yamashita M (2010) Identification of a novel selenium-containing compound, selenoneine, as the predominant chemical form of organic selenium in the blood of bluefin tuna. J Biol Chem 285, 18134-18138.

52. Yamashita Y, Yabu T \& Yamashita M (2010) Discovery of the strong antioxidant selenoneine in tuna and selenium redox metabolism. World J Biol Chem 1, 144-150.

53. O'Hagan S \& Kell DB (2017) Analysis of drug-endogenous human metabolite similarities in terms of their maximum common substructures. J Cheminform $\mathbf{9}, 18$.

54. O'Hagan S \& Kell DB (2016) MetMaxStruct: a Tverskysimilarity-based strategy for analysing the (sub)structural similarities of drugs and endogenous metabolites. Front Pharmacol 7, 266.

55. O'Hagan S \& Kell DB (2015) The KNIME workflow environment and its applications in genetic programming and machine learning. Genetic Progr Evol Mach 16, 387-391.

56. Thiele I, Swainston N, Fleming RMT, et al. (2013) A community-driven global reconstruction of human metabolism. Nat Biotechnol 31, 419-425.

57. O'Hagan S, Swainston N, Handl J, et al. (2015) A 'rule of 0.5 ' for the metabolite-likeness of approved pharmaceutical drugs. Metabolomics 11, 323-339.

58. Lewis KA, Tzilivakis J, Warner DJ, et al. (2016) An international database for pesticide risk assessments and management. Hum Ecol Risk Assess 22, 1050-1064.

59. Melville DB, Genghof DS, Inamine E, et al. (1956) Ergothioneine in microorganisms. J Biol Chem 223, 9-17.

60. Jones GW, Doyle S \& Fitzpatrick DA (2014) The evolutionary history of the genes involved in the biosynthesis of the antioxidant ergothioneine. Gene 549, 161-170.

61. Newton GL, Arnold K, Price MS, et al. (1996) Distribution of thiols in microorganisms: mycothiol is a major thiol in most actinomycetes. J Bacteriol 178, 1990-1995.

62. Dosanjh M, Newton GL \& Davies J (2008) Characterization of a mycothiol ligase mutant of Rhodococcus jostii RHA1. Res Microbiol 159, 643-650.

63. Genghof DS \& Van Damme O (1964) Biosynthesis of ergothioneine and hercynine by mycobacteria. J Bacteriol 87, 852-862.
64. Genghof DS \& Van Damme O (1968) Biosynthesis of ergothioneine from endogenous hercynine in Mycobacterium smegmatis. J Bacteriol 95, 340-344.

65. Genghof DS (1970) Biosynthesis of ergothioneine and hercynine by fungi and Actinomycetales.J Bacteriol 103, 475-478.

66. Trivedi A, Singh N, Bhat SA, et al. (2012) Redox biology of tuberculosis pathogenesis. Adv Microb Physiol 60, 263-324.

67. Narainsamy K, Farci S, Braun E, et al. (2016) Oxidative-stress detoxification and signalling in cyanobacteria: the crucial glutathione synthesis pathway supports the production of ergothioneine and ophthalmate. Mol Microbiol 100, 15-24.

68. Baran R, Bowen BP, Price MN, et al. (2013) Metabolic footprinting of mutant libraries to map metabolite utilization to genotype. ACS Chem Biol 8, 189-199.

69. Baran R, Ivanova NN, Jose N, et al. (2013) Functional genomics of novel secondary metabolites from diverse cyanobacteria using untargeted metabolomics. Mar Drugs 11, 3617-3631.

70. Pfeiffer C, Bauer T, Surek B, et al. (2011) Cyanobacteria produce high levels of ergothioneine. Food Chem 129, 1766-1769.

71. Liao C \& Seebeck FP (2017) Convergent evolution of ergothioneine biosynthesis in cyanobacteria. Chembiochemistry $\mathbf{1 8}$, 2115-2118.

72. Alamgir KM, Masuda S, Fujitani Y, et al. (2015) Production of ergothioneine by Methylobacterium species. Front Microbiol 6, 1185

73. Rawat M \& Av-Gay Y (2007) Mycothiol-dependent proteins in actinomycetes. FEMS Microbiol Rev 31, 278-292.

74. Melville DB \& Eich S (1956) The occurrence of ergothioneine in plant material. J Biol Chem 218, 647-651.

75. Baran R, Brodie EL, Mayberry-Lewis J, et al. (2015) Exometabolite niche partitioning among sympatric soil bacteria. Nat Commun 6, 8289.

76. Melville DB (1959) Ergothioneine. Vitam Horm 17, 155-204.

77. Tan CH \& Audley BG (1968) Ergothioneine and hercynine in Hevea brasiliensis latex. Phytochemistry 7, 109-118.

78. Audley BG \& Tan CH (1968) Uptake of ergothioneine from soil into latex of Hevea brasiliensis. Phytochemistry 7 , 1999-2000.

79. Warren CR (2013) Quaternary ammonium compounds can be abundant in some soils and are taken up as intact molecules by plants. New Phytol 198, 476-485.

80. Park EJ, Lee WY, Kim ST, et al. (2010) Ergothioneine accumulation in a medicinal plant Gastrodia elata.J Med Lant Res $\mathbf{4}$, $1141-1147$.

81. Guo QL, Lin S, Wang YN, et al. (2016) Gastrolatathioneine, an unusual ergothioneine derivative from an aqueous extract of "tian ma": a natural product co-produced by plant and symbiotic fungus. Chin Chem Lett 27, 1577-1581.

82. Melville DB, Otken CC \& Kovalenko V (1955) On the origin of animal ergothioneine. J Biol Chem 216, 325-331.

83. Melville DB, Horner WH, Otken CC, et al. (1955) Studies on the origin of ergothioneine in animals. $J$ Biol Chem 213 , 61-68.

84. Eagles BA \& Vars HM (1928) The physiology of ergothioneine. J Biol Chem 80, 615-622.

85. Melville DB, Horner WH \& Lubschez R (1954) Tissue ergothioneine. J Biol Chem 206, 221-228.

86. Kawano H, Otani M, Takeyama K, et al. (1982) Studies on ergothioneine. VI. Distribution and fluctuations of ergothioneine in rats. Chem Pharm Bull (Tokyo) 30, 1760-1765.

87. Tucker RAJ, Cheah IK \& Halliwell B (2019) Specificity of the ergothioneine transporter natively expressed in HeLa cells. Biochem Biophys Res Commun 513, 22-27. 
88. Bu'Lock JD (1961) Intermediary metabolism and antibiotic synthesis. Adv Microbial Physiol 3, 293-333.

89. Melville DB, Eich S \& Ludwig ML (1957) The biosynthesis of ergothioneine. J Biol Chem 224, 871-877.

90. Askari A \& Melville DB (1962) The reaction sequence in ergothioneine biosynthesis: hercynine as an intermediate. J Biol Chem 237, 1615-1618.

91. Seebeck FP (2013) Thiohistidine biosynthesis. Chimia (Aarau) 67, 333-336.

92. Seebeck FP (2010) In vitro reconstitution of mycobacterial ergothioneine biosynthesis. J Am Chem Soc 132, 6632-6633.

93. Richard-Greenblatt M, Bach H, Adamson J, et al. (2015) Regulation of ergothioneine biosynthesis and its effect on Mycobacterium tuberculosis growth and infectivity. $J$ Biol Chem 290, 23064-23076.

94. Naowarojna N, Cheng R, Chen L, et al. (2018) Mini-review: ergothioneine and ovothiol biosyntheses, an unprecedented trans-sulfur strategy in natural product biosynthesis. Biochemistry 57, 3309-3325.

95. Reinhold VN, Ishikawa Y \& Melville DB (1970) Conversion of histidine to hercynine by Neurospora crassa.J Bacteriol 101, 881-884.

96. Melville DB, Ludwig ML, Inamine E, et al. (1959) Transmethylation in the biosynthesis of ergothioneine. J Biol Chem 234, 1195-1198.

97. Ishikawa Y, Israel SE \& Melville DB (1974) Participation of an intermediate sulfoxide in the enzymatic thiolation of the imidazole ring of hercynine to form ergothioneine. $J$ Biol Chem 249, 4420-4427.

98. Leisinger F, Burn R, Meury M, et al. (2019) Structural and mechanistic basis for anaerobic ergothioneine biosynthesis. J Am Chem Soc 141, 6906-6914.

99. Burn R, Misson L, Meury M, et al. (2017) Anaerobic origin of ergothioneine. Angew Chem Int Ed Engl 56, 12508-12511.

100. Ruszczycky MW \& Liu HW (2017) The surprising history of an antioxidant. Nature 551, 37-38.

101. Goncharenko KV, Vit A, Blankenfeldt W, et al. (2015) Structure of the sulfoxide synthase EgtB from the ergothioneine biosynthetic pathway. Angew Chem Int Ed Engl 54, 2821-2824.

102. Vit A, Mashabela GT, Blankenfeldt W, et al. (2015) Structure of the ergothioneine-biosynthesis amidohydrolase EgtC. ChemBioChem 16, 1490-1496.

103. Vit A, Misson L, Blankenfeldt W, et al. (2014) Crystallization and preliminary X-ray analysis of the ergothioneinebiosynthetic methyltransferase EgtD. Acta Crystallogr $F$ Struct Biol Commun 70, 676-680.

104. Vit A, Misson L, Blankenfeldt W, et al. (2015) Ergothioneine biosynthetic methyltransferase EgtD reveals the structural basis of aromatic amino acid betaine biosynthesis. ChemBioChem 16, 119-125.

105. Misson L, Burn R, Vit A, et al. (2018) Inhibition and regulation of the ergothioneine biosynthetic methyltransferase EgtD. ACS Chem Biol 13, 1333-1342.

106. Irani S, Naowarojna N, Tang Y, et al. (2018) Snapshots of C-S cleavage in Egt2 reveals substrate specificity and reaction mechanism. Cell Chem Biol 25, 519-529.e514.

107. Naowarojna N, Irani S, Hu WY, et al. (2019) Crystal structure of the ergothioneine sulfoxide synthase from Candidatus Chloracidobacterium thermophilum and structure-guided engineering to modulate its substrate selectivity. ACS Catal 9, 6955-6961.

108. Uniprot (2019) Neurospora crassa EGT1. https://www. uniprot.org/uniprot/Q7RX33 (accessed August 2019).

109. Uniprot (2019) Mycobacterium tuberculosis EGTD. https:// www.uniprot.org/uniprot/P9WN46 (accessed August 2019).
110. Daunay S, Lebel R, Farescour L, et al. (2016) Short protectinggroup-free synthesis of 5-acetylsulfanyl-histidines in water: novel precursors of 5-sulfanyl-histidine and its analogues. Org Biomol Chem 14, 10473-10480.

111. Xu JZ \& Yadan JC (1995) Synthesis of $\mathrm{L}-(+)$-ergothioneine. J Org Chem 60, 6296-6301.

112. Khonde PL \& Jardine A (2015) Improved synthesis of the super antioxidant, ergothioneine, and its biosynthetic pathway intermediates. Org Biomol Chem 13, 1415-1419.

113. Fujitani $Y$, Alamgir KM \& Tani A (2018) Ergothioneine production using Methylobacterium species, yeast, and fungi.J Biosci Bioeng 126, 715-722.

114. Takusagawa S, Satoh Y, Ohtsu I, et al. (2019) Ergothioneine production with Aspergillus oryzae. Biosci Biotechnol Biochem 83, 181-184.

115. Osawa R, Kamide T, Satoh Y, et al. (2018) Heterologous and high production of ergothioneine in Escherichia coli. J Agric Food Chem 66, 1191-1196.

116. Tanaka N, Kawano Y, Satoh Y, et al. (2019) Gram-scale fermentative production of ergothioneine driven by overproduction of cysteine in Escherichia coli. Sci Rep 9, 1895.

117. van der Hoek SA, Darbani B, Zugaj K, et al. (2019) Engineering the yeast Saccharomyces cerevisiae for the production of L-(+)-ergothioneine. Front Bioeng Biotechnol 7, 262.

118. Li M \& Borodina I (2015) Application of synthetic biology for production of chemicals in yeast Saccharomyces cerevisiae. FEMS Yeast Res 15, 1-12.

119. O'Hagan S, Wright Muelas M, Day PJ, et al. (2018) GeneGini: assessment via the Gini coefficient of reference "housekeeping" genes and diverse human transporter expression profiles. Cell Syst 6, 230-244.

120. Chaleckis R, Ebe M, Pluskal T, et al. (2014) Unexpected similarities between the Schizosaccharomyces and human blood metabolomes, and novel human metabolites. Mol Biosyst 10, 2538-2551.

121. McMenamy RH, Lund CC \& Wallach DF (1960) Unbound amino acid concentrations in plasma, erythrocytes, leukocytes and urine of patients with leukemia. J Clin Invest 39, $1688-1705$.

122. McMenamy RH, Lund CC, Neville GJ, et al. (1960) Studies of unbound amino acid distributions in plasma, erythrocytes, leukocytes and urine of normal human subjects. J Clin Invest 39, 1675-1687.

123. Arduini A, Mancinelli G, Radatti GL, et al. (1992) Possible mechanism of inhibition of nitrite-induced oxidation of oxyhemoglobin by ergothioneine and uric acid. Arch Biochem Biophys 294, 398-402.

124. Li RWS, Yang C, Sit ASM, et al. (2014) Uptake and protective effects of ergothioneine in human endothelial cells.J Pharmacol Exp Ther 350, 691-700.

125. Weigand-Heller AJ, Kris-Etherton PM \& Beelman RB (2012) The bioavailability of ergothioneine from mushrooms (Agaricus bisporus) and the acute effects on antioxidant capacity and biomarkers of inflammation. Prev Med 54, Suppl., S75-S78

126. Reglinski J, Smith WE, Wilson R, et al. (1991) Clinical analysis in intact erythrocytes using ${ }^{1} \mathrm{H}$ spin echo NMR. Clin Chim Acta 201, 45-57.

127. Wang LZ, Thuya WL, Toh DS, et al. (2013) Quantification of L-ergothioneine in human plasma and erythrocytes by liquid chromatography-tandem mass spectrometry. J Mass Spectrom 48, 406-412.

128. Turner E, Brewster JA, Simpson NA, et al. (2009) Imidazolebased erythrocyte markers of oxidative stress in preeclampsia - an NMR investigation. Reprod Sci 16, 1040-1051. 
129. Mitsuyama H \& May JM (1999) Uptake and antioxidant effects of ergothioneine in human erythrocytes. Clin Sci (Lond) 97, 407-411.

130. Gründemann D, Harlfinger S, Golz S, et al. (2005) Discovery of the ergothioneine transporter. Proc Natl Acad Sci US A $\mathbf{1 0 2}$ 5256-5261.

131. Tang RMY, Cheah IK, Yew TSK, et al. (2018) Distribution and accumulation of dietary ergothioneine and its metabolites in mouse tissues. Sci Rep 8, 1601.

132. Nikodemus D, Lazic D, Bach M, et al. (2011) Paramount levels of ergothioneine transporter SLC22A4 mRNA in boar seminal vesicles and cross-species analysis of ergothioneine and glutathione in seminal plasma. J Physiol Pharmacol 62, 411-419.

133. Kaneko I, Takeuchi Y, Yamaoka Y, et al. (1980) Quantitative determination of ergothioneine in plasma and tissues by TLCdensitometry. Chem Pharm Bull (Tokyo) 28, 3093-3097.

134. Shires TK, Brummel MC, Pulido JS, et al. (1997) Ergothioneine distribution in bovine and porcine ocular tissues. Comp Biochem Physiol C Pharmacol Toxicol Endocrinol 117, 117-120.

135. Crossland J, Mitchell J \& Woodruff GN (1966) The presence of ergothioneine in the central nervous system and its probable identity with the cerebellar factor. J Physiol 182, 427-438.

136. Nakamichi N, Taguchi T, Hosotani H, et al. (2012) Functional expression of carnitine/organic cation transporter OCTN1 in mouse brain neurons: possible involvement in neuronal differentiation. Neurochem Int 61, 1121-1132.

137. Vermeulen E \& Vermeersch P (2012) Hepcidin as a biomarker for the diagnosis of iron metabolism disorders: a review. Acta Clin Belg 67, 190-197.

138. Ganz T \& Nemeth E (2011) The hepcidin-ferroportin system as a therapeutic target in anemias and iron overload disorders. Hematol Am Soc Hematol Educ Program 2011, 538-542.

139. Ganz T \& Nemeth E (2012) Hepcidin and iron homeostasis. Biochim Biophys Acta 1823, 1434-1443.

140. Nemeth E \& Ganz T (2009) The role of hepcidin in iron metabolism. Acta Haematol 122, 78-86.

141. Reichert CO, da Cunha J, Levy D, et al. (2017) Hepcidin: homeostasis and diseases related to iron metabolism. Acta Haematol 137, 220-236.

142. Kell DB, Swainston N, Pir P, et al. (2015) Membrane transporter engineering in industrial biotechnology and whole-cell biocatalysis. Trends Biotechnol 33, 237-246.

143. Dobson PD \& Kell DB (2008) Carrier-mediated cellular uptake of pharmaceutical drugs: an exception or the rule? Nat Rev Drug Disc 7, 205-220.

144. Kell DB \& Dobson PD (2009) The cellular uptake of pharmaceutical drugs is mainly carrier-mediated and is thus an issue not so much of biophysics but of systems biology. In Proceedings of the International Beilstein Symposium on Systems Chemistry, pp. 149-168 [MG Hicks and C Kettner, editors]. Berlin: Logos Verlag.

145. Kell DB, Dobson PD \& Oliver SG (2011) Pharmaceutical drug transport: the issues and the implications that it is essentially carrier-mediated only. Drug Disc Today 16, 704-714.

146. Kell DB, Dobson PD, Bilsland E, et al. (2013) The promiscuous binding of pharmaceutical drugs and their transportermediated uptake into cells: what we (need to) know and how we can do so. Drug Disc Today 18, 218-239.

147. Kell DB (2013) Finding novel pharmaceuticals in the systems biology era using multiple effective drug targets, phenotypic screening, and knowledge of transporters: where drug discovery went wrong and how to fix it. FEBS $J \mathbf{2 8 0}$, 5957-5980.

148. Kell DB \& Oliver SG (2014) How drugs get into cells: tested and testable predictions to help discriminate between transporter-mediated uptake and lipoidal bilayer diffusion. Front Pharmacol 5, 231.

149. Kell DB (2015) The transporter-mediated cellular uptake of pharmaceutical drugs is based on their metabolite-likeness and not on their bulk biophysical properties: towards a systems pharmacology. Perspect Sci 6, 66-83.

150. Kell DB (2016) How drugs pass through biological cell membranes - a paradigm shift in our understanding? Beilstein Magazine 2, no. 5.

151. Giacomini KM, Huang SM, Tweedie DJ, et al. (2010) Membrane transporters in drug development. Nat Rev Drug Discov 9, 215-236.

152. Dickens D, Rädisch S, Chiduza GN, et al. (2018) Cellular uptake of the atypical antipsychotic clozapine is a carriermediated process. Mol Pharm 15, 3557-3572.

153. César-Razquin A, Snijder B, Frappier-Brinton T, et al. (2015) A call for systematic research on solute carriers. Cell $\mathbf{1 6 2}$, 478-487.

154. Hediger MA, Clemencon B, Burrier RE, et al. (2013) The ABCs of membrane transporters in health and disease (SLC series): Introduction. Mol Aspects Med 34, 95-107.

155. Anonymous (2019) SLC Tables. http://www.bioparadigms. org/slc/intro.htm (accessed August 2019

156. Chen Z, Shi T, Zhang L, et al. (2016) Mammalian drug efflux transporters of the ATP binding cassette (ABC) family in multidrug resistance: a review of the past decade. Cancer Lett 370, 153-164.

157. Koepsell H (2013) The SLC22 family with transporters of organic cations, anions and zwitterions. Mol Aspects Med 34, 413-435.

158. Pochini L, Galluccio M, Scalise M, et al. (2019) OCTN: a small transporter subfamily with great relevance to human pathophysiology, drug discovery, and diagnostics. SLAS Discov 24, 89-110.

159. Garg N, Kapono C, Lim YW, et al. (2015) Mass spectral similarity for untargeted metabolomics data analysis of complex mixtures. Int J Mass Spectrom 377, 719-717.

160. Li XS, Wang Z, Cajka T, et al. (2018) Untargeted metabolomics identifies trimethyllysine, a TMAO-producing nutrient precursor, as a predictor of incident cardiovascular disease risk. JCI Insight 3, 99096

161. Coene KLM, Kluijtmans LAJ, van der Heeft E, et al. (2018) Next-generation metabolic screening: targeted and untargeted metabolomics for the diagnosis of inborn errors of metabolism in individual patients. J Inherit Metab Dis $\mathbf{4 1}$, 337-353.

162. Tautenhahn R, Cho K, Uritboonthai W, et al. (2012) An accelerated workflow for untargeted metabolomics using the METLIN database. Nature Biotechnol 30, 826-828.

163. Dunn WB, Broadhurst D, Begley P, et al. (2011) Procedures for large-scale metabolic profiling of serum and plasma using gas chromatography and liquid chromatography coupled to mass spectrometry. Nat Protoc 6, 1060-1083.

164. Dunn WB, Erban A, Weber RJM, et al. (2013) Mass appeal: metabolite identification in mass spectrometry-focused untargeted metabolomics. Metabolomics 9, Suppl. 1, S44-S66.

165. Heinzmann SS, Brown IJ, Chan Q, et al. (2010) Metabolic profiling strategy for discovery of nutritional biomarkers: proline betaine as a marker of citrus consumption. Am JClin Nutr 92, 436-443.

166. Lang R, Lang $T$, Bader $M$, et al. (2017) High-throughput quantitation of proline betaine in foods and suitability as a valid biomarker for citrus consumption. J Agric Food Chem 65, 1613-1619.

167. Lloyd AJ, Beckmann M, Favé G, et al. (2011) Proline betaine and its biotransformation products in fasting urine samples 
are potential biomarkers of habitual citrus fruit consumption. Br J Nutr 106, 812-824.

168. Gasteiger J (2003) Basic Chemoinformatics: A Textbook. Weinheim: Wiley/VCH.

169. Bacher P, Giersiefer S, Bach M, et al. (2009) Substrate discrimination by ergothioneine transporter SLC22A 4 and carnitine transporter SLC22A5: gain-of-function by interchange of selected amino acids. Biochim Biophys Acta 1788, 25942602.

170. Grigat S, Harlfinger S, Pal S, et al. (2007) Probing the substrate specificity of the ergothioneine transporter with methimazole, hercynine, and organic cations. Biochem Pharmacol 74, 309-316.

171. Gründemann D (2012) The ergothioneine transporter controls and indicates ergothioneine activity - a review. Prev Med 54, Suppl., S71-S74.

172. Tschirka J, Kreisor M, Betz J, et al. (2018) Substrate selectivity check of the ergothioneine transporter. Drug Metab Dispos 46, 779-785.

173. Shimizu T, Masuo Y, Takahashi S, et al. (2015) Organic cation transporter OCTN1-mediated uptake of food-derived antioxidant ergothioneine into infiltrating macrophages during intestinal inflammation in mice. Drug Metab Pharmacokinet 30, 231-239.

174. Yabuuchi H, Tamai I, Nezu J, et al. (1999) Novel membrane transporter OCTN1 mediates multispecific, bidirectional, and $\mathrm{pH}$-dependent transport of organic cations. J Pharmacol Exp Ther 289, 768-773.

175. Akamine T, Koyanagi S, Kusunose N, et al. (2015) Dosing time-dependent changes in the analgesic effect of pregabalin on diabetic neuropathy in mice. J Pharmacol Exp Ther 354, $65-72$.

176. Shimizu T, Kijima A, Masuo Y, et al. (2015) Gene ablation of carnitine/organic cation transporter 1 reduces gastrointestinal absorption of 5-aminosalicylate in mice. Biol Pharm Bull 38, 774-780.

177. Tamai I (2013) Pharmacological and pathophysiological roles of carnitine/organic cation transporters (OCTNs: SLC22A4, SLC22A5 and Slc22a21). Biopharm Drug Dispos 34, 29-44.

178. Nakamura T, Yoshida K, Yabuuchi H, et al. (2008) Functional characterization of ergothioneine transport by rat organic cation/carnitine transporter OCTN1 (SLC22A4). Biol Pharm Bull 31, 1580-1584.

179. Darghouth D, Giarratana MC, Oliveira L, et al. (2016) Bioengineered and native red blood cells from cord blood exhibit the same metabolomic profile. Haematologica 101, e220-e222.

180. Taubert D, Lazar A, Grimberg G, et al. (2006) Association of rheumatoid arthritis with ergothioneine levels in red blood cells: a case control study. J Rheumatol 33, 2139-2145.

181. Indiveri C, Galluccio M, Scalise M, et al. (2013) Strategies of bacterial over expression of membrane transporters relevant in human health: the successful case of the three members of OCTN subfamily. Mol Biotechnol 54, 724-736.

182. Frigeni M, Iacobazzi F, Yin X, et al. (2016) Wide tolerance to amino acids substitutions in the OCTN1 ergothioneine transporter. Biochim Biophys Acta 1860, 1334-1342.

183. Nigam SK (2018) The SLC22 transporter family: a paradigm for the impact of drug transporters on metabolic pathways, signaling, and disease. Annu Rev Pharmacol Toxicol 58, 663-687.

184. Pochini L, Scalise M, Galluccio M, et al. (2013) OCTN cation transporters in health and disease: role as drug targets and assay development. J Biomol Screen 18, 851-867.
185. Wolf KK \& Paine MF (2018) Metabolic barrier of the gastrointestinal tract. In Comprehensive Toxicology, 3rd ed., pp. 74-98 [C McQueen, editor]. Amsterdam: Elsevier.

186. Thul PJ, Åkesson L, Wiking M, et al. (2017) A subcellular map of the human proteome. Science 356, eaal3321.

187. Apostolova N \& Victor VM (2015) Molecular strategies for targeting antioxidants to mitochondria: therapeutic implications. Antioxid Redox Signal 22, 686-729.

188. Lamhonwah AM \& Tein I (2006) Novel localization of OCTN1, an organic cation/carnitine transporter, to mammalian mitochondria. Biochem Biophys Res Commun 345, 1315-1325.

189. Lamhonwah AM, Hawkins CE, Tam C, et al. (2008) Expression patterns of the organic cation/carnitine transporter family in adult murine brain. Brain Dev 30, 31-42.

190. Xuan W, Lamhonwah AM, Librach C, et al. (2003) Characterization of organic cation/carnitine transporter family in human sperm. Biochem Biophys Res Commun 306, 121-128.

191. Anonymous (2019) SLC22A4. https://www.proteinatlas.org/ ENSG00000197208-SLC22A4/cell (accessed August 2019).

192. Skogs M, Stadler C, Schutten R, et al. (2017) Antibody validation in bioimaging applications based on endogenous expression of tagged proteins. J Proteome Res 16, 147-155.

193. Edfors F, Hober A, Linderbäck K, et al. (2018) Enhanced validation of antibodies for research applications. Nat Commun 9, 4130

194. Rabia LA, Desai AA, Jhajj HS, et al. (2018) Understanding and overcoming trade-offs between antibody affinity, specificity, stability and solubility. Biochem Eng J 137, 365-374.

195. Jain D \& Salunke DM (2019) Antibody specificity and promiscuity. Biochem J 476, 433-447.

196. Edwards BM, Barash SC, Main SH, et al. (2003) The remarkable flexibility of the human antibody repertoire; isolation of over one thousand different antibodies to a single protein, BLyS. J Mol Biol 334, 103-118.

197. Vaughan TJ, Osbourn JK \& Tempest PR (1998) Human antibodies by design. Nat Biotechnol 16, 535-539.

198. Michaud GA, Salcius M, Zhou F, et al. (2003) Analyzing antibody specificity with whole proteome microarrays. Nat Biotechnol 21, 1509-1512.

199. Palmieri F (2013) The mitochondrial transporter family SLC25: identification, properties and physiopathology. Mol Aspects Med 34, 465-484.

200. Palmieri F (2014) Mitochondrial transporters of the SLC25 family and associated diseases: a review. J Inherit Metab Dis 37, 565-575.

201. Anonymous (2019) Q9H015 tree in phylome 533. http:// phylomedb.org/?q=search_tree\&seqid=Q9H015\# (accessed August 2019).

202. Anonymous (2019) GeneTree Image. http://www.ensembl.org/ Multi/GeneTree/Image?gt=ENSGT00940000154155 (accessed August 2019).

203. O'Hagan S \& Kell DB (2017) Consensus rank orderings of molecular fingerprints illustrate the 'most genuine' similarities between marketed drugs and small endogenous human metabolites, but highlight exogenous natural products as the most important 'natural' drug transporter substrates. ADMET DMPK 5, 85-125.

204. Chapy H, Smirnova M, Andre P, et al. (2014) Carrier-mediated cocaine transport at the blood-brain barrier as a putative mechanism in addiction liability. Int J Neuropsychopharmacol 18, pyu001.

205. Danchin A (2018) Bacteria in the ageing gut: did the taming of fire promote a long human lifespan? Environ Microbiol 20, 1966-1987. 
206. Kell DB \& Pretorius E (2018) No effects without causes. The iron dysregulation and dormant microbes hypothesis for chronic, inflammatory diseases. Biol Rev 93, 1518-1557.

207. Butterfield DA \& Halliwell B (2019) Oxidative stress, dysfunctional glucose metabolism and Alzheimer disease. Nat Rev Neurosci 20, 148-160.

208. Kell DB (2009) Iron behaving badly: inappropriate iron chelation as a major contributor to the aetiology of vascular and other progressive inflammatory and degenerative diseases. BMC Med Genomics 2, 2.

209. Babior BM (2000) Phagocytes and oxidative stress. Am J Med 109, 33-44.

210. Cave AC, Brewer AC, Narayanapanicker A, et al. (2006) NADPH oxidases in cardiovascular health and disease. Antioxid Redox Signal 8, 691-728.

211. Bedard K \& Krause KH (2007) The NOX family of ROSgenerating NADPH oxidases: physiology and pathophysiology. Physiol Rev 87, 245-313.

212. Wardman P \& Candeias LP (1996) Fenton chemistry: an introduction. Rad Res 145, 523-531.

213. Kell DB (2010) Towards a unifying, systems biology understanding of large-scale cellular death and destruction caused by poorly liganded iron: Parkinson's, Huntington's, Alzheimer's, prions, bactericides, chemical toxicology and others as examples. Arch Toxicol 577, 825-889.

214. Winston GW, Feierman DE \& Cederbaum AI (1984) The role of iron chelates in hydroxyl radical production by rat liver microsomes, NADPH-cytochrome P-450 reductase and xanthine oxidase. Arch Biochem Biophys 232, 378-390.

215. Fong A \& Hieftje GM (1995) Near-IR multiplex bandpass spectrometer utilizing liquid molecular filters. Appl Spectrosc $\mathbf{4 9}$ 493-498.

216. Kehrer JP (2000) The Haber-Weiss reaction and mechanisms of toxicity. Toxicology 149, 43-50.

217. Kell DB \& Pretorius E (2014) Serum ferritin is an important disease marker, and is mainly a leakage product from damaged cells. Metallomics 6, 748-773.

218. Valachová K, Mach M, Dubovický M, et al. (2019) The importance of ergothioneine synthesis in ancient time by organisms living in oxygen free atmosphere. Med Hypotheses 123, $72-73$.

219. Migliore L, Fontana I, Colognato R, et al. (2005) Searching for the role and the most suitable biomarkers of oxidative stress in Alzheimer's disease and in other neurodegenerative diseases. Neurobiol Aging 26, 587-595.

220. Ahsan H (2013) 3-Nitrotyrosine: a biomarker of nitrogen free radical species modified proteins in systemic autoimmunogenic conditions. Hum Immunol 74, 1392-1399.

221. Bartesaghi S \& Radi R (2018) Fundamentals on the biochemistry of peroxynitrite and protein tyrosine nitration. Redox Biol 14, 618-625.

222. Ryberg H \& Caidahl K (2007) Chromatographic and mass spectrometric methods for quantitative determination of 3-nitrotyrosine in biological samples and their application to human samples. J Chromatogr B 851, 160-171.

223. Rahman I (2012) Pharmacological antioxidant strategies as therapeutic interventions for COPD. Biochim Biophys Acta 1822, 714-728.

224. Aruoma OI, Whiteman M, England TG, et al. (1997) Antioxidant action of ergothioneine: assessment of its ability to scavenge peroxynitrite. Biochem Biophys Res Commun 231, 389-391.

225. Halliwell B (1997) What nitrates tyrosine? Is nitrotyrosine specific as a biomarker of peroxynitrite formation in vivo? FEBS Lett 411, 157-160.
226. Ferrer-Sueta G, Campolo N, Trujillo M, et al. (2018) Biochemistry of peroxynitrite and protein tyrosine nitration. Chem Rev 118, 1338-1408.

227. Petersen DR \& Doorn JA (2004) Reactions of 4-hydroxynonenal with proteins and cellular targets. Free Radic Biol Med 37, 937-945.

228. Akanmu D, Cecchini R, Aruoma OI, et al. (1991) The antioxidant action of ergothioneine. Arch Biochem Biophys 288, 10-16.

229. Asmus KD, Bensasson RV, Bernier JL, et al. (1996) Oneelectron oxidation of ergothioneine and analogues investigated by pulse radiolysis: redox reaction involving ergothioneine and vitamin C. Biochem J 315, 625-629.

230. Motohashi N \& Mori I (1986) Thiol-induced hydroxyl radical formation and scavenger effect of thiocarbamides on hydroxyl radicals. J Inorg Biochem 26, 205-212.

231. Jang JH, Aruoma OI, Jen LS, et al. (2004) Ergothioneine rescues PC12 cells from $\beta$-amyloid-induced apoptotic death. Free Radic Biol Med 36, 288-299.

232. Chaudière J \& Ferrari-Iliou R (1999) Intracellular antioxidants: from chemical to biochemical mechanisms. Food Chem Toxicol 37, 949-962.

233. Oumari M, Goldfuss B, Stoffels C, et al. (2019) Regeneration of ergothioneine after reaction with singlet oxygen. Free Radic Biol Med 134, 498-504.

234. Devasagayam TPA, Sundquist AR, Di Mascio P, et al. (1991) Activity of thiols as singlet molecular oxygen quenchers. J Photochem Photobiol B 9, 105-116.

235. Hartman PE, Hartman Z \& Ault KT (1990) Scavenging of singlet molecular oxygen by imidazole compounds: high and sustained activities of carboxy terminal histidine dipeptides and exceptional activity of imidazole-4-acetic acid. Photochem Photobiol 51, 59-66.

236. van den Broeke LT \& Beyersbergen van Henegouwen GM (1993) Thiols as potential UV radiation protectors: an in vitro study. J Photochem Photobiol B 17, 279-286.

237. Egorov S, Kurella EG, Boldyrev AA, et al. (1997) Quenching of singlet molecular oxygen by carnosine and related antioxidants. Monitoring 1270-nm phosphorescence in aqueous media. Biochem Mol Biol Int 41, 687-694.

238. Boldyrev A \& Abe H (1999) Metabolic transformation of neuropeptide carnosine modifies its biological activity. Cell Mol Neurobiol 19, 163-175.

239. Dahl TA, Midden WR \& Hartman PE (1988) Some prevalent biomolecules as defenses against singlet oxygen damage. Photochem Photobiol 47, 357-362.

240. Dong KK, Damaghi N, Kibitel J, et al. (2007) A comparison of the relative antioxidant potency of L-ergothioneine and idebenone. J Cosmet Dermatol 6, 183-188.

241. Obayashi K, Kurihara K, Okano Y, et al. (2005) L-Ergothioneine scavenges superoxide and singlet oxygen and suppresses TNF- $\alpha$ and MMP-1 expression in UV-irradiated human dermal fibroblasts. J Cosmet Sci 56, 17-27.

242. Stoffels C, Oumari M, Perrou A, et al. (2017) Ergothioneine stands out from hercynine in the reaction with singlet oxygen: resistance to glutathione and TRIS in the generation of specific products indicates high reactivity. Free Radic Biol Med 113, 385-394.

243. He QC, Krone K, Scherl D, et al. (2004) The use of ozone as an oxidizing agent to evaluate antioxidant activities of natural substrates. Skin Pharmacol Physiol 17, 183-189.

244. Markova NG, Karaman-Jurukovska N, Dong KK, et al. (2009) Skin cells and tissue are capable of using L-ergothioneine as an integral component of their antioxidant defense system. Free Radic Biol Med 46, 1168-1176. 
245. Nguyen TH, Nagasaka R \& Ohshima T (2013) The natural antioxidant ergothioneine: resources, chemical characterization, and applications. In Lipid Oxidation: Challenges in Food Systems, pp. 381-415 [A Logan, U Nienaber and X Pan, editors]. Urbana, IL: AOCS Press.

246. Servillo L, D'Onofrio N, Casale R, et al. (2017) Ergothioneine products derived by superoxide oxidation in endothelial cells exposed to high-glucose. Free Radic Biol Med 108, 8-18.

247. Bello MH, Barrera-Perez V, Morin D, et al. (2012) The Neurospora crassa mutant Nc $\Delta E g t-1$ identifies an ergothioneine biosynthetic gene and demonstrates that ergothioneine enhances conidial survival and protects against peroxide toxicity during conidial germination. Fungal Genet Biol 49, 160-172.

248. Hartman PE (1990) Ergothioneine as antioxidant. Meth Enzymol 186, 310-318.

249. Asahi T, Wu X, Shimoda H, et al. (2016) A mushroom-derived amino acid, ergothioneine, is a potential inhibitor of inflammation-related DNA halogenation. Biosci Biotechnol Biochem 80, 313-317.

250. Whiteman M \& Halliwell B (1997) Thiols and disulphides can aggravate peroxynitrite-dependent inactivation of $\alpha 1$-antiproteinase. FEBS Lett 414, 497-500.

251. Aruoma OI, Spencer JPE \& Mahmood N (1999) Protection against oxidative damage and cell death by the natural antioxidant ergothioneine. Food Chem Toxicol 37, 1043-1053.

252. Garay AS (1956) On the effect of some protective and stimulatory substances in honey-dew on the germination of ergot conidia. Physiol Plantarum 9, 344-349.

253. Garay AS (1956) Role of ergothioneine and catalase in infection by ergot fungus (Claviceps purpurea Tul.). Nature 177, 91-92.

254. Sao Emani C, Williams MJ, Wiid IJ, et al. (2013) Ergothioneine is a secreted antioxidant in Mycobacterium smegmatis. Antimicrob Agents Chemother 57, 3202-3207.

255. Nakajima S, Satoh Y, Yanashima K, et al. (2015) Ergothioneine protects Streptomyces coelicolor A3(2) from oxidative stresses. J Biosci Bioeng 120, 294-298.

256. Liu H, Zhao X, Guo M, et al. (2015) Growth and metabolism of Beauveria bassiana spores and mycelia. BMC Microbiol 15, 267.

257. Sheridan KJ, Lechner BE, Keeffe GO, et al. (2016) Ergothioneine biosynthesis and functionality in the opportunistic fungal pathogen, Aspergillus fumigatus. Sci Rep 6, 35306.

258. Ta P, Buchmeier N, Newton GL, et al. (2011) Organic hydroperoxide resistance protein and ergothioneine compensate for loss of mycothiol in Mycobacterium smegmatis mutants. J Bacteriol 193, 1981-1990.

259. Cumming BM, Lamprecht DA, Wells RM, et al. (2014) The physiology and genetics of oxidative stress in mycobacteria. Microbiol Spectr 2 (epublication 2 May 2014).

260. Cumming BM, Chinta KC, Reddy VP, et al. (2018) Role of ergothioneine in microbial physiology and pathogenesis. Antioxid Redox Signal 28, 431-444.

261. Farhana A, Guidry L, Srivastava A, et al. (2010) Reductive stress in microbes: implications for understanding Mycobacterium tuberculosis disease and persistence. Adv Microb Physiol 57, 43-117.

262. Kurutas EB (2016) The importance of antioxidants which play the role in cellular response against oxidative/nitrosative stress: current state. Nutr J 15, 71.

263. Cardoso SM (2019) Special issue: the antioxidant capacities of natural products. Molecules 24, 492-495.

264. Ooi BK, Chan K-G, Goh BH, et al. (2018) The role of natural products in targeting cardiovascular diseases via $\mathrm{Nrf} 2$ pathway: novel molecular mechanisms and therapeutic approaches. Front Pharmacol 9, 1308.

265. Urquiaga I \& Leighton F (2000) Plant polyphenol antioxidants and oxidative stress. Biol Res 33, 55-64.

266. Chen W, Jia Z, Pan MH, et al. (2016) Natural products for the prevention of oxidative stress-related diseases: mechanisms and strategies. Oxid Med Cell Longev 2016, 4628502.

267. Salehi B, Stojanović-Radić Z, Matejić J, et al. (2019) The therapeutic potential of curcumin: a review of clinical trials. Eur J Med Chem 163, 527-545.

268. Gonçalves PB, Romeiro NC (2019) Multi-target natural products as alternatives against oxidative stress in chronic obstructive pulmonary disease (COPD). Eur J Med Chem 163, 911-931.

269. Jia ZQ, Anandh Babu PV, Chen W, et al. (2018) Natural products targeting on oxidative stress and inflammation: mechanisms, therapies, and safety assessment. Oxid Med Cell Longev 2018, 6576093.

270. Davey HM \& Kell DB (1996) Flow cytometry and cell sorting of heterogeneous microbial populations: the importance of single-cell analysis. Microbiol Rev 60, 641-696.

271. Savoie J-M, Minvielle N \& Largeteau ML (2008) Radicalscavenging properties of extracts from the white button mushroom, Agaricus bisporus. J Sci Food Agric 88, 870-875.

272. Yokota ME, Frison PS, Marcante RC, et al. (2016) Iron translocation in Pleurotus ostreatus basidiocarps: production, bioavailability, and antioxidant activity. Genet Mol Res 15.

273. Kozarski M, Klaus A, Jakovljevic D, et al. (2015) Antioxidants of edible mushrooms. Molecules 20, 19489-19525.

274. Zhao H, Zhang M, Liu Q, et al. (2018) A comprehensive screening shows that ergothioneine is the most abundant antioxidant in the wild macrofungus Phylloporia ribis Ryvarden. J Environ Sci Health C 36, 98-111.

275. Dubost NJ, Ou B \& Beelman RB (2007) Quantification of polyphenols and ergothioneine in cultivated mushrooms and correlation to total antioxidant capacity. Food Chem 105, 727-735.

276. Liao WC, Wu WH, Tsai PC, et al. (2012) Kinetics of ergothioneine inhibition of mushroom tyrosinase. Appl Biochem Biotechnol 166, 259-267.

277. Kell DB, Kaprelyants AS \& Grafen A (1995) On pheromones, social behaviour and the functions of secondary metabolism in bacteria. Trends Ecol Evolution 10, 126-129.

278. Gallagher L, Owens RA, Dolan SK, et al. (2012) The Aspergillus fumigatus protein GliK protects against oxidative stress and is essential for gliotoxin biosynthesis. Eukaryot Cell 11, 1226-1238.

279. Song H, Her AS, Raso F, et al. (2014) Cysteine oxidation reactions catalyzed by a mononuclear non-heme iron enzyme (OvoA) in ovothiol biosynthesis. Org Lett 16, 2122-2125.

280. Castellano I \& Seebeck FP (2018) On ovothiol biosynthesis and biological roles: from life in the ocean to therapeutic potential. Nat Prod Rep 35, 1241-1250.

281. Vázquez-Fresno R, Rosana ARR, Sajed T, et al. (2019) Herbs and spices- biomarkers of intake based on human intervention studies - a systematic review. Genes Nutr 14, 18.

282. Menon VP \& Sudheer AR (2007) Antioxidant and antiinflammatory properties of curcumin. Adv Exp Med Biol 595, 105-125.

283. Abrahams S, Haylett WL, Johnson G, et al. (2019) Antioxidant effects of curcumin in models of neurodegeneration, aging, oxidative and nitrosative stress: a review. Neuroscience 406, 1-21.

284. Li H, Sureda A, Devkota HP, et al. (2019) Curcumin, the golden spice in treating cardiovascular diseases. Biotechnol 
$A d v$ 2019, S0734-9750(19)30010-2 (epublication ahead of print version 1 February 2019).

285. Sanei M \& Saberi-Demneh A (2019) Effect of curcumin on memory impairment: a systematic review. Phytomedicine 52, 98-106.

286. Tomeh MA, Hadianamrei R \& Zhao X (2019) A review of curcumin and its derivatives as anticancer agents. Int JMol Sci $\mathbf{2 0}$, E1033.

287. Pekkinen J, Rosa-Sibakov N, Micard V, et al. (2015) Amino acid-derived betaines dominate as urinary markers for rye bran intake in mice fed high-fat diet - a nontargeted metabolomics study. Mol Nutr Food Res 59, 1550-1562.

288. Kempf B \& Bremer E (1998) Uptake and synthesis of compatible solutes as microbial stress responses to high-osmolality environments. Arch Microbiol 170, 319-330.

289. Roberts MF (2005) Organic compatible solutes of halotolerant and halophilic microorganisms. Saline Systems 1, 5 .

290. Wani SH, Singh NB, Haribhushan A, et al. (2013) Compatible solute engineering in plants for abiotic stress tolerance - role of glycine betaine. Curr Genomics 14, 157-165.

291. Weinand M, Krämer R, Morbach S (2007) Characterization of compatible solute transporter multiplicity in Corynebacterium glutamicum. Appl Microbiol Biotechnol 76, 701-708.

292. Imhoff JF \& Rodriguez-Valera F (1984) Betaine is the main compatible solute of halophilic eubacteria. Bacteriology 160, 478-479.

293. Fahnert B (2012) Using folding promoting agents in recombinant protein production: a review. Methods Mol Biol 824, 3-36.

294. Ey J, Schömig E \& Taubert D (2007) Dietary sources and antioxidant effects of ergothioneine. J Agric Food Chem $\mathbf{5 5}$ 6466-6474.

295. Lee DP, Alexander D \& Jonnalgadda SS (2013) Diversity of nutrient content in grains - a pilot metabolomics analysis. J Nutr Food Sci 3, 10.4172/2155-9600.1000191.

296. Wang Y, Gapstur SM, Carter BD, et al. (2018) Untargeted metabolomics identifies novel potential biomarkers of habitual food intake in a cross-sectional study of postmenopausal women. J Nutr 148, 932-943.

297. Pallister T, Jennings A, Mohney RP, et al. (2016) Characterizing blood metabolomics profiles associated with self-reported food intakes in female twins. PLOS ONE 11, e0158568.

298. Dubost NJ, Beelman RB, Peterson D, et al. (2005) Identification and quantification of ergothioneine in cultivated mushrooms by liquid chromatography-mass spectroscopy. Int J Med Mush 8, 215-222.

299. Dubost NJ, Beelman RB \& Royse DJ (2007) Influence of selected cultural factors and postharvest storage on ergothioneine content of common button mushroom Agaricus bisporus (J. Lge) Imbach (Agaricomycetideae). Int J Med Mush 9, 163-176.

300. Kalaras MD, Richie JP, Calcagnotto A, et al. (2017) Mushrooms: a rich source of the antioxidants ergothioneine and glutathione. Food Chem 233, 429-433.

301. Tepwong P \& Ohshima T (2009) Biosynthesis of ergothioneine during different stages of submerged fermentation of "Shiitake" (Lentinus edodes) mushroom and their bioactive properties. J Biosci Bioeng 108, S4-S5.

302. Tepwong P, Giri A \& Ohshima T (2012) Effect of mycelial morphology on ergothioneine production during liquid fermentation of Lentinula edodes. Mycoscience $\mathbf{5 3}$, 102-112.

303. Tepwong P, Giri A, Sasaki F, et al. (2012) Mycobial enhancement of ergothioneine by submerged cultivation of edible mushroom mycelia and its application as an antioxidative compound. Food Chem 131, 247-258.
304. Kalaras MD, Beelman RB \& Elias RJ (2012) Effects of postharvest pulsed UV light treatment of white button mushrooms (Agaricus bisporus) on vitamin D-2 content and quality attributes. J Agric Food Chem 60, 220-225.

305. Kalaras MD, Beelman RB, Holick MF, et al. (2012) Generation of potentially bioactive ergosterol-derived products following pulsed ultraviolet light exposure of mushrooms (Agaricus bisporus). Food Chem 135, 396-401.

306. Liang CH, Ho KJ, Huang LY, et al. (2013) Antioxidant properties of fruiting bodies, mycelia, and fermented products of the culinary-medicinal king oyster mushroom, Pleurotus eryngii (higher Basidiomycetes), with high ergothioneine content. Int J Med Mushrooms 15, 267-275.

307. Lin SY, Chien SC, Wang SY, et al. (2015) Submerged cultivation of mycelium with high ergothioneine content from the culinary-medicinal golden oyster mushroom, Pleurotus citrinopileatus (higher Basidiomycetes). Int $J$ Med Mushrooms 17, 749-761.

308. Lin SY, Chien SC, Wang SY, et al. (2016) Nonvolatile taste components and antioxidant properties of fruiting body and mycelium with high ergothioneine content from the culinarymedicinal golden oyster mushroom Pleurotus citrinopileatus (Agaricomycetes). Int J Med Mushrooms 18, 689-698.

309. Chen SY, Ho KJ, Hsieh YJ, et al. (2012) Contents of lovastatin, $\gamma$-aminobutyric acid and ergothioneine in mushroom fruiting bodies and mycelia. LWT Food Sci Technol 47, 274-278.

310. Peñaloza W, Davey CL, Hedger JN, et al. (1991) Stimulation by potassium ions of the growth of Rhizopus oligosporus during liquid- and solid-substrate fermentations. World J Microbiol Biotechnol 7, 260-268.

311. Peñaloza W, Davey CL, Hedger JN, et al. (1992) Physiological studies on the solid-state quinoa tempe fermentation, using on-line measurements of fungal biomass production. $J$ Sci Food Agric 59, 227-235.

312. Karyadi D \& Lukito W (1996) Beneficial effects of tempeh in disease prevention and treatment. Nutr Rev 54, S94-S98.

313. Lukito W (2001) Candidate foods in the Asia-Pacific region for cardiovascular protection: nuts, soy, lentils and tempe. Asia Pac J Clin Nutr 10, 128-133.

314. Nout MJR \& Kiers JL (2005) Tempe fermentation, innovation and functionality: update into the third millenium. $J$ Appl Microbiol 98, 789-805.

315. Guinard JX, Myrdal Miller A, Mills K, et al. (2016) Consumer acceptance of dishes in which beef has been partially substituted with mushrooms and sodium has been reduced. Appetite 105, 449-459.

316. Myrdal Miller A, Mills K, Wong T, et al. (2014) Flavorenhancing properties of mushrooms in meat-based dishes in which sodium has been reduced and meat has been partially substituted with mushrooms. J Food Sci 79, S1795-S1804.

317. Royse DJ, Baars J \& Tan Q (2017) Current overview of mushroom production in the world. In Edible and Medicinal Mushrooms: Technology and Applications, pp. 5-14 [DC Zied and A Pardo-Giménez, editors]. New York: Wiley-Blackwell.

318. Gallego P, Rojas A, Falcón G, et al. (2019) Water-soluble extracts from edible mushrooms (Agaricus bisporus) as inhibitors of hepatitis C viral replication. Food Funct 10, 3758-3767.

319. Schmitz LK (2015) Bioavailability and antioxidant effect of ergothioneine in human blood. MaRBLe Res Pap 6, 174-183.

320. Dogan A, Dalar A, Sadullahoglu C, et al. (2018) Investigation of the protective effects of horse mushroom (Agaricus arvensis Schaeff.) against carbon tetrachloride-induced oxidative stress in rats. Mol Biol Rep 45, 787-797.

321. Khatun K, Mahtab H, Khanam PA, et al. (2007) Oyster mushroom reduced blood glucose and cholesterol in diabetic subjects. Mymensingh Med J 16, 94-99. 
322. Hess J, Wang Q, Gould T, et al. (2018) Impact of Agaricus bisporus mushroom consumption on gut health markers in healthy adults. Nutrients 10, E1402.

323. Chaturvedi VK, Agarwal S, Gupta KK, et al. (2018) Medicinal mushroom: boon for therapeutic applications. 3 Biotech $\mathbf{8}, 334$.

324. Moro C, Palacios I, Lozano M, et al. (2012) Anti-inflammatory activity of methanolic extracts from edible mushrooms in LPS activated RAW 264.7 macrophages. Food Chem 130, 350-355.

325. Guillamón E, García-Lafuente A, Lozano M, et al. (2010) Edible mushrooms: role in the prevention of cardiovascular diseases. Fitoterapia 81, 715-723.

326. Friedman M (2015) Chemistry, nutrition, and healthpromoting properties of Hericium erinaceus (lion's mane) mushroom fruiting bodies and mycelia and their bioactive compounds. J Agric Food Chem 63, 7108-7123.

327. Moon B \& Lo YM (2014) Conventional and novel applications of edible mushrooms in today's food industry. J Food Process Pres 38, 2146-2153.

328. Tang C, Hoo PC, Tan LT, et al. (2016) Golden needle mushroom: a culinary medicine with evidenced-based biological activities and health promoting properties. Front Pharmacol 7, 474 .

329. Jayakumar T, Sakthivel M, Thomas PA, et al. (2008) Pleurotus ostreatus, an oyster mushroom, decreases the oxidative stress induced by carbon tetrachloride in rat kidneys, heart and brain. Chem-Biol Interact 176, 108-120.

330. Jayakumar T, Thomas PA, Sheu JR, et al. (2011) In vitro and in vivo antioxidant effects of the oyster mushroom Pleurotus ostreatus. Food Res Int 44, 851-861.

331. Jayakumar T, Thomas PA, Ramesh E, et al. (2010) An extract of the Pleurotus ostreatus mushroom bolsters the glutathione redox system in various organs of aged rats. J Med Food 13, 771-778.

332. Rahman MA, Abdullah N \& Aminudin N (2017) Corroborative assessment of mushroom as the graceful ageing and lifespan promoting agent. Biointerface Res App 7, 2072-2083.

333. Rahman MA, Abdullah N \& Aminudin N (2016) Interpretation of mushroom as a common therapeutic agent for Alzheimer's disease and cardiovascular diseases. Crit Rev Biotechnol 36 , 1131-1142.

334. Feeney MJ, Dwyer J, Hasler-Lewis CM, et al. (2014) Mushrooms and health summit proceedings. J Nutr 144, 1128S-1136S.

335. Feeney MJ, Miller AM, Roupas P (2014) Mushrooms biologically distinct and nutritionally unique: exploring a "third food kingdom". Nutr Today 49, 301-307.

336. Kawaguchi Y, Nirengi S, Kotani K, et al. (2017) Mushroom intake and advanced glycation end products in the skin among community-dwelling elderly subjects: preliminary data.J Biomed 2, 8-11.

337. Benson KF, Ager DM, Landes B, et al. (2012) Improvement of joint range of motion (ROM) and reduction of chronic pain after consumption of an ergothioneine-containing nutritional supplement. Prev Med 54, Suppl., S83-S89.

338. Gargano ML, van Griensven LJLD, Isikhuemhen OS, et al. (2017) Medicinal mushrooms: valuable biological resources of high exploitation potential. Plant Biosystems 151, 548-565.

339. Khan MA \& Tania M (2012) Nutritional and medicinal importance of Pleurotus mushrooms: an overview. Food Rev Int 28, 313-329.

340. Calvo MS, Mehrotra A, Beelman RB, et al. (2016) A retrospective study in adults with metabolic syndrome: diabetic risk factor response to daily consumption of Agaricus bisporus (white button mushrooms). Plant Foods Hum Nutr 71, 245-251.

341. Mori K, Inatomi S, Ouchi K, et al. (2009) Improving effects of the mushroom Yamabushitake (Hericium erinaceus) on mild cognitive impairment: a double-blind placebo-controlled clinical trial. Phytother Res 23, 367-372.

342. Roncero-Ramos I \& Delgado-Andrade C (2017) The beneficial role of edible mushrooms in human health. Curr Opin Food Sci 14, 122-128.

343. Reis FS, Martins A, Vasconcelos MH, et al. (2017) Functional foods based on extracts or compounds derived from mushrooms. Trends Food Sci Tech 66, 48-62.

344. Soković M, Glamočlija J, Ćirić A, et al. (2018) Mushrooms as sources of therapeutic foods. In Therapeutic Foods, vol. 8, pp. 141-178 [AM Holban and AM Grumezescu, editors]. Cambridge, MA: Academy Press.

345. Trovato Salinaro A, Pennisi M, Di Paola R, et al. (2018) Neuroinflammation and neurohormesis in the pathogenesis of Alzheimer's disease and Alzheimer-linked pathologies: modulation by nutritional mushrooms. Immun Ageing 15, 8 .

346. Valverde ME, Hernandez-Perez T \& Paredes-Lopez O (2015) Edible mushrooms: improving human health and promoting quality life. Int J Microbiol 2015, 376387.

347. Muszyńska B, Grzywacz-Kisielewska A, Kała K, et al. (2018) Anti-inflammatory properties of edible mushrooms: a review. Food Chem 243, 373-381.

348. Feng L, Cheah IK, Ng MM, et al. (2019) The association between mushroom consumption and mild cognitive impairment: a community-based cross-sectional study in Singapore. J Alzheimers Dis 68, 197-203.

349. Poddar KH, Ames M, Hsin-Jen C, et al. (2013) Positive effect of mushrooms substituted for meat on body weight, body composition, and health parameters. A 1-year randomized clinical trial. Appetite 71, 379-387.

350. Hodge AM \& Calvo MS (2019) Do bioactive components in non-animal food sources contribute to the beneficial health effect of a Japanese dietary pattern? Public Health Nutr 22, 2469-2471.

351. Zembron-Lacny A, Gajewski M, Naczk M, et al. (2013) Effect of shiitake (Lentinus edodes) extract on antioxidant and inflammatory response to prolonged eccentric exercise. J Physiol Pharmacol 64, 249-254.

352. Jayachandran M, Xiao J \& Xu B (2017) A critical review on health promoting benefits of edible mushrooms through gut microbiota. Int J Mol Sci 18, E1934.

353. Maier L, Pruteanu M, Kuhn M, et al. (2018) Extensive impact of non-antibiotic drugs on human gut bacteria. Nature $\mathbf{5 5 5}$, 623-628.

354. Schmutz M, Carron PN, Yersin B, et al. (2018) Mushroom poisoning: a retrospective study concerning 11-years of admissions in a Swiss emergency department. Intern Emerg Med 13, 59-67.

355. Chan CK, Lam HC, Chiu SW, et al. (2016) Mushroom poisoning in Hong Kong: a ten-year review. Hong Kong Med J 22, 124-130.

356. Verma N, Bhalla A, Kumar S, et al. (2014) Wild mushroom poisoning in north India: case series with review of literature. J Clin Exp Hepatol 4, 361-365.

357. White J, Weinstein SA, De Haro L, et al. (2019) Mushroom poisoning: a proposed new clinical classification. Toxicon 157, 53-65.

358. Ramirez-Martinez A, Wesolek N, Yadan JC, et al. (2016) Intake assessment of L-ergothioneine in some European countries and in the United States. Hum Ecol Risk Assess 22, 667-677.

359. Marone PA, Trampota J, Weisman S (2016) A safety evaluation of a nature-identical L-ergothioneine in Sprague Dawley rats. Int J Toxicol 35, 568-583.

360. Cheah IK, Tang RMY, Yew TSZ, et al. (2017) Administration of pure ergothioneine to healthy human subjects: uptake, 
metabolism, and effects on biomarkers of oxidative damage and inflammation. Antioxid Redox Signal 26, 193-206.

361. Turck D, Bresson JL, Burlingame B, et al. (2016) Safety of synthetic L-ergothioneine (Ergoneine $(\mathrm{R})$ ) as a novel food pursuant to Regulation (EC) No 258/97. EFSA J 14, 4629.

362. Turck D, Bresson JL, Burlingame B, et al. (2017) Statement on the safety of synthetic L-ergothioneine as a novel food supplementary dietary exposure and safety assessment for infants and young children, pregnant and breastfeeding women. EFSA J 15, 5060.

363. Schauss AG, Vértesi A, Endres JR, et al. (2010) Evaluation of the safety of the dietary antioxidant ergothioneine using the bacterial reverse mutation assay. Toxicology 278, 39-45.

364. Schauss AG, Béres E, Vértesi A, et al. (2011) The effect of ergothioneine on clastogenic potential and mutagenic activity: genotoxicity evaluation. Int J Toxicol 30, 405-409.

365. Hunter G (1928) A new test for ergothioneine upon which is based a method for its estimation in simple solution and in blood-filtrates. Biochem J 22, 4-10.

366. Melville DB \& Lubschez R (1953) A method for the determination of ergothioneine in blood. J Biol Chem 200, 275-285.

367. Carlsson J, Kierstan MP \& Brocklehurst K (1974) A convenient spectrophotometric assay for the determination of L-ergothioneine in blood. Biochem J 139, 237-242.

368. Sotgia S, Arru D, Sotgiu E, et al. (2016) Simultaneous determination of the main amino thiol and thione in human whole blood by CE and LC. Bioanalysis 8, 945-951.

369. Sotgia S, Pisanu E, Pintus G, et al. (2013) Plasma L-ergothioneine measurement by high-performance liquid chromatography and capillary electrophoresis after a precolumn derivatization with 5-iodoacetamidofluorescein (5-IAF) and fluorescence detection. PLOS ONE 8, e70374.

370. Zhou T, Liu Q, Jiang W, et al. (2012) A new strategy for quantitative analysis of ergothioneine in fermentation broth by RP-HPLC. Lect Notes Elec Eng 249, 313-321.

371. Mayumi T, Kawano H, Sakamoto Y, et al. (1978) Studies on ergothioneine. V. Determination by high performance liquid chromatography and application to metabolic research. Chem Pharm Bull (Tokyo) 26, 3772-3778.

372. Sotgia S, Zinellu A, Arru D, et al. (2015) Amniotic fluid L-ergothioneine concentrations in pregnant sheep after natural mating and transfer of vitrified/thawed in-vitro produced embryos. Res Vet Sci 102, 238-241.

373. Liu Q, Zhang W, Wang H, et al. (2016) Validation of a HILIC method for the analysis of ergothioneine in fermentation broth. J Chromatogr Sci 54, 934-938.

374. Muda M, Pelizzoni F, Sello G, et al. (1988) Determination of ergothioneine in red blood cells by high-performance liquid chromatography. J Chromatogr 434, 191-195.

375. Newton GL, Dorian R \& Fahey RC (1981) Analysis of biological thiols: derivatization with monobromobimane and separation by reverse-phase high-performance liquid chromatography. Anal Biochem 114, 383-387.

376. Bello MH, Mogannam JC, Morin D, et al. (2014) Endogenous ergothioneine is required for wild type levels of conidiogenesis and conidial survival but does not protect against $254 \mathrm{~nm}$ UV-induced mutagenesis or kill. Fungal Genet Biol 73, 120-127.

377. Fahey RC \& Newton GL (1987) Determination of lowmolecular-weight thiols using monobromobimane fluorescent labeling and high-performance liquid chromatography. Methods Enzymol 143, 85-96.

378. Sotgia S, Pisanu E, Cambedda D, et al. (2014) Ultraperformance liquid chromatographic determination of L-ergothioneine in commercially available classes of cow milk. J Food Sci 79, C1683-C1687.
379. Kuninori T \& Nishiyama J (1991) Measurement of biological thiols and disulfides by high-performance liquid chromatography and electrochemical detection of silver mercaptide formation. Anal Biochem 197, 19-24.

380. Kroepfl N, Francesconi KA, Schwerdtle T, et al. (2019) Selenoneine and ergothioneine in human blood cells determined simultaneously by HPLC/ICPQQQ-MS. J Anal At Spectrom 34, 127-134.

381. Bashir R (2017) Bio-analytical screening and characterization of antioxidant compounds using online liquid chromatography techniques and mass spectrometry. Thesis for Doctor of Philosophy, Swinburne University of Technology.

382. Sotgia S, Zinellu A, Pintus G, et al. (2013) Quantification of L-ergothioneine in whole blood by hydrophilic interaction ultra-performance liquid chromatography and UV-detection. J Sep Sci 36, 1002-1006.

383. Sakurai H \& Takeshima S (1977) Acid dissociation of 2-mercaptohistamine and its related compounds. Talanta 24, 531-532.

384. Bessieres MA, Gibon Y, Lefeuvre JC, et al. (1999) A single-step purification for glycine betaine determination in plant extracts by isocratic HPLC. J Agric Food Chem 47, 3718-3722.

385. Kar JR \& Singhal RS (2017) Pilot scale production, kinetic modeling, and purification of glycine betaine and trehalose produced from Actinopolyspora halophila (MTCC 263) using acid whey: a dairy industry effluent. Chem Eng Sci 163, 83-91.

386. Bubnik Z, Pour V, Gruberova A, et al. (2004) Application of continuous chromatographic separation in sugar processing. J Food Eng 61, 509-513.

387. Kumosani TA (2001) L-Ergothioneine level in red blood cells of healthy human males in the Western province of Saudi Arabia. Exp Mol Med 33, 20-22.

388. Baldridge RC \& Lewis HB (1953) Diet and the ergothioneine content of blood. J Biol Chem 202, 169-176.

389. Baldridge RC (1955) Blood ergothioneine and dietary oats. J Nutr 56, 107-113.

390. Teruya T, Chaleckis R, Takada J, et al. (2019) Diverse metabolic reactions activated during 58 -hr fasting are revealed by non-targeted metabolomic analysis of human blood. Sci Rep $\mathbf{9}, 854$.

391. Cheah IK, Feng L, Tang RMY, et al. (2016) Ergothioneine levels in an elderly population decrease with age and incidence of cognitive decline; a risk factor for neurodegeneration? Biochem Biophys Res Commun 478, 162-167.

392. Yan S, Wu B, Lin Z, et al. (2009) Metabonomic characterization of aging and investigation on the anti-aging effects of total flavones of Epimedium. Mol Biosyst 5, 1204-1213.

393. Dang VT, Shi Y \& Werstuck G (2015) Comprehensive metabolomic analysis of diabetic atherosclerosis. Can J Cardiol 31, S229.

394. Leone E, Mann T (1951) Ergothioneine in the seminal vesicle secretion. Nature 168, 205-206.

395. Strzeżek R, Koziorowska-Gilun M, Kowalowka M, et al. (2009) Characteristics of antioxidant system in dog semen. Pol J Vet Sci 12, 55-60.

396. Strzeżek R, Koziorowska-Gilun M, Kielczewski K, et al. (2015) Effect of dialysis of dog semen on sperm characteristics and some biochemical components of seminal plasma. Pol J Vet Sci 18, 447-448.

397. Kenny LC \& Kell DB (2018) Immunological tolerance, pregnancy and preeclampsia: the roles of semen microbes and the father. Front Med Obs Gynecol 4, 239.

398. Forster R, Spézia F, Papineau D, et al. (2015) Reproductive safety evaluation of L-ergothioneine. Food Chem Toxicol $\mathbf{8 0}$, 85-91.

399. Mishra A, Reddy IJ, Dhali A, et al. (2018) L-Ergothioneine improves the developmental potential of in vitro sheep embryos 
without influencing OCTN1-mediated cross-membrane transcript expression. Zygote 26, 149-161.

400. Shukla Y, Kulshrestha OP \& Khuteta KP (1981) Ergothioneine content in normal and senile human cataractous lenses. Indian J Med Res 73, 472-473.

401. Kato Y, Kubo Y, Iwata D, et al. (2010) Gene knockout and metabolome analysis of carnitine/organic cation transporter OCTN1. Pharm Res 27, 832-840.

402. Chaleckis R, Murakami I, Takada J, et al. (2016) Individual variability in human blood metabolites identifies age-related differences. Proc Natl Acad Sci U S A 113, 4252-4259.

403. Jose JM (2011) Ergothioneine degradation and properties of ergothionase from Agrobacterium radiobacter. BSc Thesis, Penn State University.

404. Kelly B, Appleman MD (1961) Degradation of ergothioneine by cell-free extracts of Alcaligenes faecalis. J Bacteriol $\mathbf{8 1}$, 715-720.

405. Muramatsu H, Matsuo H, Okada N, et al. (2013) Characterization of ergothionase from Burkholderia sp. HME13 and its application to enzymatic quantification of ergothioneine. Appl Microbiol Biotechnol 97, 5389-5400.

406. Yanasugondha D \& Appleman MD (1957) Degradation of ergothioneine by Alcaligenes faecalis. J Bacteriol $\mathbf{7 4}$, 381-385.

407. Fennema D, Phillips IR \& Shephard EA (2016) Trimethylamine and trimethylamine $\mathrm{N}$-oxide, a flavin-containing monooxygenase 3 (FMO3)-mediated host-microbiome metabolic axis implicated in health and disease. Drug Metab Dispos 44, $1839-1850$

408. Wolff JB (1962) Ergothionase from Escherichia coli. J Biol Chem 237, 874-881.

409. Maurer A, Leisinger F, Lim D, et al. (2019) Structure and mechanism of ergothionase from Treponema denticola. Chemistry 25, 10298-10303.

410. Booth JS, Appleman MD (1963) Degradation of ergothioneine by cell-free extracts of Alcaligenes faecalis. II. Production of glutamic acid. J Bacteriol 85, 654-657.

411. Cheah IK, Ong RL, Gruber J, et al. (2013) Knockout of a putative ergothioneine transporter in Caenorbabditis elegans decreases lifespan and increases susceptibility to oxidative damage. Free Radic Res 47, 1036-1045.

412. Ben Said M, Grati M, Ishimoto T, et al. (2016) A mutation in SLC22A4 encoding an organic cation transporter expressed in the cochlea strial endothelium causes human recessive non-syndromic hearing loss DFNB60. Hum Genet 135, 513-524.

413. Urban TJ, Yang C, Lagpacan LL, et al. (2007) Functional effects of protein sequence polymorphisms in the organic cation/ ergothioneine transporter OCTN1 (SLC22A4). Pharmacogenet Genomics 17, 773-782.

414. Toh DSL, Koo SH, Limenta LMG, et al. (2009) Genetic variations of the SLC22A4 gene in Chinese and Indian populations of Singapore. Drug Metab Pharmacokinet 24, 475-481.

415. Toh DSL, Cheung FSG, Murray M, et al. (2013) Functional analysis of novel variants in the organic cation/ergothioneine transporter 1 identified in Singapore populations. Mol Pharm 10, 2509-2516.

416. Mathieson I, Lazaridis I, Rohland N, et al. (2015) Genomewide patterns of selection in 230 ancient Eurasians. Nature 528, 499-503.

417. Yamase Y, Horibe H, Ueyama C, et al. (2015) Association of TOMM40 and SLC22A4 polymorphisms with ischemic stroke. Biomed Rep 3, 491-498.

418. Nakamura T, Sugiura S, Kobayashi D, et al. (2007) Decreased proliferation and erythroid differentiation of K562 cells by
siRNA-induced depression of OCTN1 (SLC22A4) transporter gene. Pharm Res 24, 1628-1635.

419. Maeda T, Hirayama M, Kobayashi D, et al. (2007) Mechanism of the regulation of organic cation/carnitine transporter 1 (SLC22A4) by rheumatoid arthritis-associated transcriptional factor RUNX1 and inflammatory cytokines. Drug Metab Dispos 35, 394-401.

420. Tokuhiro S, Yamada R, Chang X, et al. (2003) An intronic SNP in a RUNX1 binding site of SLC22A4, encoding an organic cation transporter, is associated with rheumatoid arthritis. Nat Genet 35, 341-348.

421. Reglinski J, Smith WE \& Sturrock RD (1988) Spin-echo ${ }^{1} \mathrm{H}$ NMR detected response of ergothioneine to oxidative stress in the intact human erythrocyte. Magn Reson Med 6, 217-223.

422. Takata Y, Inoue H, Sato A, et al. (2008) Replication of reported genetic associations of PADI4, FCRL3, SLC22A4 and RUNX1 genes with rheumatoid arthritis: results of an independent Japanese population and evidence from meta-analysis of East Asian studies. J Hum Genet 53, 163-173.

423. Barton A, Eyre S, Bowes J, et al. (2005) Investigation of the SLC22A4 gene (associated with rheumatoid arthritis in a Japanese population) in a United Kingdom population of rheumatoid arthritis patients. Arthritis Rheum 52, 752-758.

424. Han TU, Lee HS, Kang C, et al. (2015) Association of joint erosion with SLC22A4 gene polymorphisms inconsistently associated with rheumatoid arthritis susceptibility. Autoimmunity 48, 313-317.

425. Martínez A, Valdivia A, Pascual-Salcedo D, et al. (2006) Role of SLC22A4, SLC22A5, and RUNX1 genes in rheumatoid arthritis. J Rheumatol 33, 842-846.

426. Yamada R, Tokuhiro S, Chang X, et al. (2004) SLC22A4 and RUNX1: identification of RA susceptible genes. $J$ Mol Med (Berl) 82, 558-564.

427. Lee YH, Bae SC, Kim JH, et al. (2015) Meta-analysis of SLC22A 4 and RUNX1 polymorphisms: associations with rheumatoid arthritis susceptibility. Z Rheumatol 74, 351-358.

428. Orozco G, Sánchez E, Gómez LM, et al. (2006) Study of the role of functional variants of SLC22A4, RUNX1 and SUMO4 in systemic lupus erythematosus. Ann Rheum Dis 65, 791-795.

429. Taubert D, Grimberg G, Jung N, et al. (2005) Functional role of the $503 \mathrm{~F}$ variant of the organic cation transporter OCTN1 in Crohn's disease. Gut 54, 1505-1506.

430. Taubert D, Jung N, Goeser T, et al. (2009) Increased ergothioneine tissue concentrations in carriers of the Crohn's disease risk-associated $503 \mathrm{~F}$ variant of the organic cation transporter OCTN1. Gut 58, 312-314.

431. Jung ES, Park HJ, Kong KA, et al. (2017) Association study between OCTN1 functional haplotypes and Crohn's disease in a Korean population. Korean J Physiol Pharmacol 21, 11-17.

432. Lai Y, Xue J, Liu CW, et al. (2019) Serum metabolomics identifies altered bioenergetics, signaling cascades in parallel with exposome markers in Crohn's disease. Molecules 24, 449.

433. Huff CD, Witherspoon DJ, Zhang Y, et al. (2012) Crohn's disease and genetic hitchhiking at IBD5. Mol Biol Evol 29, 101-111.

434. Peltekova VD, Wintle RF, Rubin LA, et al. (2004) Functional variants of OCTN cation transporter genes are associated with Crohn disease. Nat Genet 36, 471-475.

435. Newman B, Gu X, Wintle R, et al. (2005) A risk haplotype in the solute carrier family $22 \mathrm{~A} 4 / 22 \mathrm{~A} 5$ gene cluster influences phenotypic expression of Crohn's disease. Gastroenterology 128, 260-269.

436. Leung E, Hong J, Fraser AG, et al. (2006) Polymorphisms in the organic cation transporter genes SLC22A4 and SLC22A5 
and Crohn's disease in a New Zealand Caucasian cohort. Immunol Cell Biol 84, 233-236.

437. Santiago JL, Martinez A, de la Calle H, et al. (2006) Evidence for the association of the SLC22A 4 and SLC22A5 genes with type 1 diabetes: a case control study. BMC Med Genet 7, 54 .

438. Zhao Z, Reece EA (2013) New concepts in diabetic embryopathy. Clin Lab Med 33, 207-233.

439. Wada E, Koyanagi S, Kusunose N, et al. (2015) Modulation of peroxisome proliferator-activated receptor- $\alpha$ activity by bile acids causes circadian changes in the intestinal expression of Octn1/Slc22a4 in mice. Mol Pharmacol 87, 314-322.

440. Mestres J, Gregori-Puigjané E, Valverde S, et al. (2009) The topology of drug-target interaction networks: implicit dependence on drug properties and target families. Mol Biosyst 5, 1051-1057.

441. Kell DB (2006) Metabolomics, modelling and machine learning in systems biology: towards an understanding of the languages of cells. The 2005 Theodor Bücher lecture. FEBS J $\mathbf{2 7 3}$ 873-894.

442. Palsson В $\varnothing$ (2015) Systems Biology: Constraint-Based Reconstruction and Analysis. Cambridge: Cambridge University Press.

443. Sastry AV, Gao Y, Szubin R, et al. (2019) The Escherichia coli transcriptome consists of independently regulated modules. Nat Commun 10, 5536.

444. Kell DB (2005) Metabolomics, machine learning and modelling: towards an understanding of the language of cells. Biochem Soc Trans 33, 520-524.

445. Kell DB \& Knowles JD (2006) The role of modeling in systems biology. In System Modeling in Cellular Biology: From Concepts to Nuts and Bolts, pp. 3-18 [Z Szallasi, J Stelling and V Periwal, editors]. Cambridge, MA: MIT Press.

446. Ihekwaba AEC, Broomhead DS, Grimley R, et al. (2004) Sensitivity analysis of parameters controlling oscillatory signalling in the NF-kB pathway: the roles of IKK and IkBa. Systems Biol 1, 93-103.

447. Saltelli A, Tarantola S, Campolongo F, et al. (2004) Sensitivity Analysis in Practice: A Guide to Assessing Scientific Models. New York: Wiley.

448. Rand DA (2008) Mapping global sensitivity of cellular network dynamics: sensitivity heat maps and a global summation law. $J R$ Soc Interface 5, Suppl. 1, S59-S69.

449. Kell DB \& Oliver SG (2004) Here is the evidence, now what is the hypothesis? The complementary roles of inductive and hypothesis-driven science in the post-genomic era. Bioessays 26, 99-105.

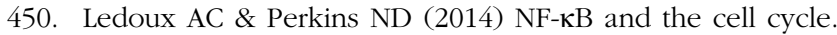
Biochem Soc Trans 42, 76-81.

451. Perkins ND (2012) The diverse and complex roles of NF-кB subunits in cancer. Nat Rev Cancer 12, 121-132.

452. Shih RH, Wang CY \& Yang CM (2015) NF-kB signaling pathways in neurological inflammation: a mini review. Front $\mathrm{Mol}$ Neurosci 8, 77.

453. Nelson DE, Ihekwaba AEC, Elliott M, et al. (2004) Oscillations in NF-kB signalling control the dynamics of gene expression. Science 306, 704-708.

454. Ashall L, Horton CA, Nelson DE, et al. (2009) Pulsatile stimulation determines timing and specificity of NFK-B-dependent transcription. Science 324, 242-246.

455. Buelna-Chontal M \& Zazueta C (2013) Redox activation of Nrf2 \& NF-кB: a double end sword? Cell Signal 25, 2548-2557.

456. Kaur U, Banerjee P, Bir A, et al. (2015) Reactive oxygen species, redox signaling and neuroinflammation in Alzheimer's disease: the NF-кB connection. Curr Top Med Chem 15, $446-457$.
457. Lepetsos P, Papavassiliou KA \& Papavassiliou AG (2019) Redox and NF-kB signaling in osteoarthritis. Free Radic Biol Med 132, 90-100.

458. Gao G \& Dudley SC Jr (2009) Redox regulation, NF-кB, and atrial fibrillation. Antioxid Redox Signal 11, 2265-2277.

459. Xiao L, Zhao L, Li T, et al. (2006) Activity of the dietary antioxidant ergothioneine in a virus gene-based assay for inhibitors of HIV transcription. Biofactors 27, 157-165.

460. Rahman I, Gilmour PS, Jimenez LA, et al. (2003) Ergothioneine inhibits oxidative stress- and TNF- $\alpha$-induced NF- $\kappa$ B activation and interleukin- 8 release in alveolar epithelial cells. Biochem Biophys Res Commun 302, 860-864.

461. Agarwal A, Aponte-Mellado A, Premkumar BJ, et al. (2012) The effects of oxidative stress on female reproduction: a review. Reprod Biol Endocrinol 10, 49.

462. Aouache R, Biquard L, Vaiman D, et al. (2018) Oxidative stress in preeclampsia and placental diseases. Int J Med Sci 19.

463. Wang J, Schipper HM, Velly AM, et al. (2015) Salivary biomarkers of oxidative stress: a critical review. Free Radic Biol Med 85, 95-104.

464. Schrag M, Mueller C, Zabel M, et al. (2013) Oxidative stress in blood in Alzheimer's disease and mild cognitive impairment: a meta-analysis. Neurobiol Dis 59, 100-110.

465. Jones DP (2006) Redefining oxidative stress. Antioxid Redox Signal 8, 1865-1879.

466. Rice-Evans CA \& Packer L (editors) (2003) Flavonoids in Health and Disease, 2nd ed. New York: Marcel Dekker.

467. Halliwell B \& Gutteridge JMC (2006) Free Radicals in Biology and Medicine, 4th ed. Oxford: Oxford University Press.

468. Halliwell B \& Gutteridge JMC (2015) Free Radicals in Biology and Medicine, 5th ed. Oxford: Oxford University Press.

469. Deiana M, Rosa A, Casu V, et al. (2004) L-Ergothioneine modulates oxidative damage in the kidney and liver of rats in vivo: studies upon the profile of polyunsaturated fatty acids. Clin Nutr 23, 183-193.

470. Laurenza I, Colognato R, Migliore L, et al. (2008) Modulation of palmitic acid-induced cell death by ergothioneine: evidence of an anti-inflammatory action. Biofactors 33, 237-247.

471. Gökçe G, Arun MZ \& Ertuna E (2018) Ergothioneine prevents endothelial dysfunction induced by mercury chloride. Exp Ther Med 15, 4697-4702.

472. Rai RK, Chalana A, Karri R, et al. (2019) Role of hydrogen bonding by thiones in protecting biomolecules from copper(I)-mediated oxidative damage. Inorg Chem 58, 6628-6638

473. Zhu BZ, Mao L, Fan RM, et al. (2011) Ergothioneine prevents copper-induced oxidative damage to DNA and protein by forming a redox-inactive ergothioneine-copper complex. Chem Res Toxicol 24, 30-34.

474. Gokce G \& Arun MZ (2014) Ergothioneine produces relaxation in isolated rat aorta by inactivating superoxide anion. Eur Rev Med Pharmacol Sci 18, 3339-3345.

475. Pahila J, Ishikawa Y \& Ohshima T (2019) Effects of ergothioneine-rich mushroom extract on the oxidative stability of astaxanthin in liposomes. J Agric Food Chem 67, 3491-3501.

476. Cheah IK, Tang R, Ye P, et al. (2016) Liver ergothioneine accumulation in a guinea pig model of non-alcoholic fatty liver disease. A possible mechanism of defence? Free Radic Res $\mathbf{5 0}$, $14-25$.

477. Sansbury BE, DeMartino AM, Xie Z, et al. (2014) Metabolomic analysis of pressure-overloaded and infarcted mouse hearts. Circ Heart Fail 7, 634-642.

478. Agudo-Barriuso M, Lahoz A, Nadal-Nicolás FM, et al. (2013) Metabolomic changes in the rat retina after optic nerve crush. Invest Ophthalmol Vis Sci 54, 4249-4259. 
479. Colognato R, Laurenza I, Fontana I, et al. (2006) Modulation of hydrogen peroxide-induced DNA damage, MAPKs activation and cell death in PC12 by ergothioneine. Clin Nutr 25, 135-145.

480. Song TY, Chen CL, Liao JW, et al. (2010) Ergothioneine protects against neuronal injury induced by cisplatin both in vitro and in vivo. Food Chem Toxicol 48, 3492-3499.

481. Nishida K, Takeuchi K, Hosoda A, et al. (2018) Ergothioneine ameliorates oxaliplatin-induced peripheral neuropathy in rats. Life Sci 207, 516-524.

482. D'Onofrio N, Servillo L, Giovane A, et al. (2016) Ergothioneine oxidation in the protection against high-glucose induced endothelial senescence: involvement of SIRT1 and SIRT6. Free Radic Biol Med 96, 211-222.

483. Gunawardena D, Bennett L, Shanmugam K, et al. (2014) Anti-inflammatory effects of five commercially available mushroom species determined in lipopolysaccharide and interferon- $\gamma$ activated murine macrophages. Food Chem 148, 92-96.

484. Sakrak O, Kerem M, Bedirli A, et al. (2008) Ergothioneine modulates proinflammatory cytokines and heat shock protein 70 in mesenteric ischemia and reperfusion injury. J Surg Res 144, 36-42.

485. Bedirli A, Sakrak O, Muhtaroglu S, et al. (2004) Ergothioneine pretreatment protects the liver from ischemia-reperfusion injury caused by increasing hepatic heat shock protein 70 . J Surg Res 122, 96-102.

486. Arduini A, Eddy L \& Hochstein P (1990) The reduction of ferryl myoglobin by ergothioneine: a novel function for ergothioneine. Arch Biochem Biophys 281, 41-43.

487. Zimring JC, Smith N, Stowell SR, et al. (2014) Strain-specific red blood cell storage, metabolism, and eicosanoid generation in a mouse model. Transfusion 54, 137-148.

488. Kell DB \& Pretorius E (2015) On the translocation of bacteria and their lipopolysaccharides between blood and peripheral locations in chronic, inflammatory diseases: the central roles of LPS and LPS-induced cell death. Integr Biol 7, 1339-1377.

489. Goodman M, Bostick RM, Kucuk O, et al. (2011) Clinical trials of antioxidants as cancer prevention agents: past, present, and future. Free Radic Biol Med 51, 1068-1084.

490. Lloret A, Esteve D, Monllor P, et al. (2019) The effectiveness of vitamin E treatment in Alzheimer's disease. Int J Mol Sci 20, E879.

491. Lloret A, Badía MC, Mora NJ, et al. (2009) Vitamin E paradox in Alzheimer's disease: it does not prevent loss of cognition and may even be detrimental. J Alzheimers Dis 17, 143-149.

492. Poston L, Briley AL, Seed PT, et al. (2006) Vitamin C and vitamin $\mathrm{E}$ in pregnant women at risk for pre-eclampsia (VIP trial): randomised placebo-controlled trial. Lancet 367, 1145-1154.

493. Oldham KM \& Bowen PE (1998) Oxidative stress in critical care: is antioxidant supplementation beneficial? J Am Diet Assoc 98, 1001-1008.

494. Rehman A, Collis CS, Yang M, et al. (1998) The effects of iron and vitamin C co-supplementation on oxidative damage to DNA in healthy volunteers. Biochem Biophys Res Comm 246, 293-298.

495. Cuzzocrea S, Riley DP, Caputi AP, et al. (2001) Antioxidant therapy: a new pharmacological approach in shock, inflammation, and ischemia/reperfusion injury. Pharmacol Rev 53, 135-159

496. Gilgun-Sherki Y, Rosenbaum Z, Melamed E, et al. (2002) Antioxidant therapy in acute central nervous system injury: current state. Pharmacol Rev 54, 271-284.

497. Miller ER 3rd, Pastor-Barriuso R, Dalal D, et al. (2005) Metaanalysis: high-dosage vitamin E supplementation may increase all-cause mortality. Ann Intern Med 142, 37-46.
498. Vaziri ND \& Rodriguez-Iturbe B (2006) Mechanisms of disease: oxidative stress and inflammation in the pathogenesis of hypertension. Nat Clin Pract Nephrol 2, 582-593.

499. Rodrigo R, Guichard C \& Charles R (2007) Clinical pharmacology and therapeutic use of antioxidant vitamins. Fund Clin Pharmacol 21, 111-127.

500. Bjelakovic G, Nikolova D, Gluud LL, et al. (2007) Mortality in randomized trials of antioxidant supplements for primary and secondary prevention: systematic review and meta-analysis. JAMA 297, 842-857.

501. Bjelakovic G, Nikolova D, Gluud LL, et al. (2008) Antioxidant supplements for prevention of mortality in healthy participants and patients with various diseases. Cochrane Database Syst Rev, issue 2, CD007176.

502. Mendes-da-Silva RF, Lopes-de-Morais AA, Bandim-da-Silva ME, et al. (2014) Prooxidant versus antioxidant brain action of ascorbic acid in well-nourished and malnourished rats as a function of dose: a cortical spreading depression and malondialdehyde analysis. Neuropharmacology $\mathbf{8 6}$, 155-160.

503. Zhang P \& Omaye ST (2001) Antioxidant and prooxidant roles for $\beta$-carotene, $\alpha$-tocopherol and ascorbic acid in human lung cells. Toxicol In Vitro 15, 13-24.

504. Ullah MF, Khan HY, Zubair H, et al. (2011) The antioxidant ascorbic acid mobilizes nuclear copper leading to a prooxidant breakage of cellular DNA: implications for chemotherapeutic action against cancer. Cancer Chemother Pharmacol 67, 103-110.

505. Repine JE \& Elkins ND (2012) Effect of ergothioneine on acute lung injury and inflammation in cytokine insufflated rats. Prev Med 54, Suppl., S79-S82.

506. Martin KR (2010) The bioactive agent ergothioneine, a key component of dietary mushrooms, inhibits monocyte binding to endothelial cells characteristic of early cardiovascular disease. J Med Food 13, 1340-1346.

507. Servillo L, D'Onofrio N \& Balestrieri ML (2017) Ergothioneine antioxidant function: from chemistry to cardiovascular therapeutic potential. J Cardiovasc Pharmacol 69, 183-191.

508. Darghouth D, Koehl B, Heilier JF, et al. (2011) Alterations of red blood cell metabolome in overhydrated hereditary stomatocytosis. Haematologica 96, 1861-1865.

509. Smith E, Ottosson F, Hellstrand S, et al. (2019) Ergothioneine is associated with reduced mortality and decreased risk of cardiovascular disease. Heart 2019, heartjnl-2019-315485 (epublication ahead of print version 31 October 2019).

510. Nurk E, Refsum H, Drevon CA, et al. (2010) Cognitive performance among the elderly in relation to the intake of plant foods. The Hordaland Health Study. BrJ Nutr 104, 1190-1201.

511. Zhang S, Tomata Y, Sugiyama K, et al. (2017) Mushroom consumption and incident dementia in elderly Japanese: the Ohsaki Cohort 2006 Study. J Am Geriatr Soc 65, 1462-1469.

512. Phan CW, David P \& Sabaratnam V (2017) Edible and medicinal mushrooms: emerging brain food for the mitigation of neurodegenerative diseases. J Med Food 20, 1-10.

513. Thangthaeng N, Miller MG, Gomes SM, et al. (2015) Daily supplementation with mushroom (Agaricus bisporus) improves balance and working memory in aged rats. Nutr Res 35, 1079-1084.

514. Tsuk S, Lev YH, Rotstein A, et al. (2017) Clinical effects of a commercial supplement of Ophiocordyceps sinensis and Ganoderma lucidum on cognitive function of healthy young volunteers. Int J Med Mushrooms 19, 667-673.

515. Hatano T, Saiki S, Okuzumi A, et al. (2016) Identification of novel biomarkers for Parkinson's disease by metabolomic technologies. J Neurol Neurosurg Psychiatry 87, 295-301. 
516. Hang L, Basil AH \& Lim KL (2016) Nutraceuticals in Parkinson's disease. Neuromolecular Med 18, 306-321.

517. Shao Y \& Le W (2019) Recent advances and perspectives of metabolomics-based investigations in Parkinson's disease. Mol Neurodegener 14, 3 .

518. Shah SP \& Duda JE (2015) Dietary modifications in Parkinson's disease: a neuroprotective intervention? Med Hypotheses $\mathbf{8 5}$, 1002-1005.

519. Graham SF, Chevallier OP, Kumar P, et al. (2017) Metabolomic profiling of brain from infants who died from sudden infant death syndrome reveals novel predictive biomarkers. J Perinatol 37, 91-97.

520. Yang NC, Lin HC, Wu JH, et al. (2012) Ergothioneine protects against neuronal injury induced by $\beta$-amyloid in mice. Food Chem Toxicol 50, 3902-3911.

521. Cheah IK, Ng LT, Ng LF, et al. (2019) Inhibition of amyloidinduced toxicity by ergothioneine in a transgenic Caenorhabditis elegans model. FEBS Lett 593, 2139-2150.

522. Nakamichi N, Nakayama K, Ishimoto T, et al. (2016) Foodderived hydrophilic antioxidant ergothioneine is distributed to the brain and exerts antidepressant effect in mice. Brain Behav 6, e00477.

523. Logan AS, Nienaber U \& Pan XS (editors) (2013) Lipid Oxidation: Challenges in Food Systems. Urbana, IL: AOCS Press.

524. Gray JI, Gomaa EA \& Buckley DJ (1996) Oxidative quality and shelf life of meats. Meat Sci 43, S111-S123.

525. Gülçin I (2012) Antioxidant activity of food constituents: an overview. Arch Toxicol 86, 345-391.

526. Perron NR \& Brumaghim JL (2009) A review of the antioxidant mechanisms of polyphenol compounds related to iron binding. Cell Biochem Biophys 53, 75-100.

527. Hanlon DP (1971) Interaction of ergothioneine with metal ions and metalloenzymes. J Med Chem 14, 1084-1087.

528. Encarnacion AB, Fagutao F, Hirono I, et al. (2010) Effects of ergothioneine from mushrooms (Flammulina velutipes) on melanosis and lipid oxidation of kuruma shrimp (Marsupenaeus japonicus). J Agric Food Chem 58, 2577-2585.

529. Encarnacion AB, Fagutao F, Hirayama J, et al. (2011) Edible mushroom (Flammulina velutipes) extract inhibits melanosis in Kuruma shrimp (Marsupenaeus japonicus). J Food Sci 76, C52-C58.

530. Bao HND, Ushio H \& Ohshima T (2009) Antioxidative activities of mushroom (Flammulina velutipes) extract added to bigeye tuna meat: dose-dependent efficacy and comparison with other biological antioxidants. J Food Sci 74, C162-C169.

531. Encarnacion AB, Fagutao F, Jintasataporn O, et al. (2012) Application of ergothioneine-rich extract from an edible mushroom Flammulina velutipes for melanosis prevention in shrimp, Penaeus monodon and Litopenaeus vannamei. Food Res Int 45, 232-237.

532. Cai LY, Li XP, Wu XS, et al. (2014) Effect of chitosan coating enriched with ergothioneine on quality changes of Japanese sea bass (Lateolabrax japonicas). Food Bioproc Technol 7 , 2281-2290.

533. Pahila J, Kaneda H, Nagasaka R, et al. (2017) Effects of ergothioneine-rich mushroom extracts on lipid oxidation and discoloration in salmon muscle stored at low temperatures. Food Chem 233, 273-281.

534. Bao HND, Ushio H \& Ohshima T (2008) Antioxidative activity and antidiscoloration efficacy of ergothioneine in mushroom (Flammulina velutipes) extract added to beef and fish meats.J Agric Food Chem 56, 10032-10040.

535. Bao HND, Osako K \& Ohshima T (2010) Value-added use of mushroom ergothioneine as a colour stabilizer in processed fish meats. J Sci Food Agric 90, 1634-1641.
536. Muszyńska B \& Sułkowska-Ziaja K (2015) Impact of food processing on non-hallucinogenic indole derivatives in edible mushrooms. In Processing and Impact on Active Components in Food, pp. 55-62 [V Preedy, editor]. San Diego, CA: Academic Press.

537. Cremades O, Diaz-Herrero MM, Carbonero-Aguilar P, et al. (2015) White button mushroom ergothione in eaqueous extracts obtained by the application of enzymes and membrane technology. Food Biosci 10, 42-47.

538. Sánchez C (2017) Reactive oxygen species and antioxidant properties from mushrooms. Synth Syst Biotechnol 2, $13-22$.

539. Duy Bao HN \& Ohshima $T$ (2013) Strategies to minimize oxidative deterioration in aquatic food products: application of natural antioxidants from edible mushrooms. In Lipid Oxidation, pp. 345-380 [U Nienaber and X Pan, editors]. Urbana, IL: AOCS Press.

540. Pérez-Sánchez A, Barrajón-Catalán E, Herranz-López M, et al. (2018) Nutraceuticals for skin care: a comprehensive review of human clinical studies. Nutrients 10, E403.

541. Lee CM (2016) Fifty years of research and development of cosmeceuticals: a contemporary review. J Cosmet Dermatol 15, 527-539.

542. Epstein H (2009) Cosmeceuticals and polyphenols. Clin Dermatol 27, 475-478.

543. Taofiq O, González-Paramás AM, Martins A, et al. (2016) Mushrooms extracts and compounds in cosmetics, cosmeceuticals and nutricosmetics - a review. Industrial Crops Products 90, 38-48.

544. Wu Y, Choi M-H, Li J, et al. (2016) Mushroom cosmetics: the present and future. Cosmetics $\mathbf{3}, 22$.

545. Linder J (2012) Cosmeceutical treatment of the aging face. In Aesthetic Medicine, pp. 69-84 [PM Prendergast and MA Shiffman, editors]. Berlin: Springer.

546. Cronin H, Draelos ZD (2010) Top 10 botanical ingredients in 2010 anti-aging creams. J Cosmet Dermatol 9, 218-225.

547. Souyoul SA, Saussy KP \& Lupo MP (2018) Nutraceuticals: a review. Dermatol Ther (Heidelb) 8, 5-16.

548. Norins AL (1962) Free radical formation in the skin following exposure to ultraviolet light. J Invest Dermatol 39, 445-448.

549. Hseu YC, Lo HW, Korivi M, et al. (2015) Dermato-protective properties of ergothioneine through induction of Nrf2/AREmediated antioxidant genes in UVA-irradiated human keratinocytes. Free Radic Biol Med 86, 102-117.

550. Botta C, Di Giorgio C, Sabatier AS, et al. (2008) Genotoxicity of visible light (400-800 $\mathrm{nm}$ ) and photoprotection assessment of ectoin, L-ergothioneine and mannitol and four sunscreens. J Photochem Photobiol B 91, 24-34.

551. Bazela K, Solyga-Zurek A, Debowska R, et al. (2014) L-Ergothioneine protects skin cells against UV-induced damage - a preliminary study. Cosmetics $\mathbf{1}, 51-60$.

552. Sao Emani C, Williams MJ, Van Helden PD, et al. (2018) $\gamma$-Glutamylcysteine protects ergothioneine-deficient Mycobacterium tuberculosis mutants against oxidative and nitrosative stress. Biochem Biophys Res Commun 495, 174-178.

553. Sao Emani C, Williams MJ, Van Helden PD, et al. (2018) Generation and characterization of thiol-deficient Mycobacterium tuberculosis mutants. Sci Data 5, 180184.

554. Jothivasan VK \& Hamilton CJ (2008) Mycothiol: synthesis, biosynthesis and biological functions of the major low molecular weight thiol in actinomycetes. Nat Prod Rep 25, 1091-1117.

555. Feng J, Che Y, Milse J, et al. (2006) The gene ncgl2918 encodes a novel maleylpyruvate isomerase that needs mycothiol as cofactor and links mycothiol biosynthesis and gentisate 
assimilation in Corynebacterium glutamicum. J Biol Chem 281, 10778-10785.

556. Newton GL, Buchmeier N \& Fahey RC (2008) Biosynthesis and functions of mycothiol, the unique protective thiol of Actinobacteria. Microbiol Mol Biol Rev 72, 471-494.

557. Bzymek KP, Newton GL, Ta P, et al. (2007) Mycothiol import by Mycobacterium smegmatis and function as a resource for metabolic precursors and energy production.J Bacteriol 189, 6796-6805.

558. Brummel MC (1985) In search of a physiological function for L-ergothioneine. Med Hypotheses 18, 351-370.

559. Brummel MC (1989) In search of a physiological function for L-ergothioneine - II. Med Hypotheses 30, 39-48.

560. Wang M, Zhao Q \& Liu W (2015) The versatile low-molecularweight thiols: beyond cell protection. Bioessays 37, 1262-1267.

561. Zhao Q, Wang M, Xu D, et al. (2015) Metabolic coupling of two small-molecule thiols programs the biosynthesis of lincomycin A. Nature 518, 115-119.

562. Goldberg A (1959) The enzymic formation of haem by the incorporation of iron into protoporphyrin; importance of ascorbic acid, ergothioneine and glutathione. Br J Haematol 5, 150-157.

563. Anonymous (2019) Clinical trials with mushrooms. https:// clinicaltrials.gov/ct2/results?cond=\&term $=$ mushrooms\&cntry $=$ $\&$ state $=\&$ city $=\& d i s t=($ accessed January 2020$)$.

564. Cheah IK (2018) Investigating the efficacy of ergothioneine to delay cognitive decline. https://clinicaltrials.gov/ct2/show/ NCT03641404 (accessed August 2019).

565. Gamage AM, Liao C, Cheah IK, et al. (2018) The proteobacterial species Burkholderia pseudomallei produces ergothioneine, which enhances virulence in mammalian infection. FASEB J 2018, fj201800716.

566. Heath H \& Wildy J (1956) Biosynthesis of ergothioneine and histidine by claviceps-purpurea. 1 . Incorporation of $\left[2-{ }^{14} \mathrm{C}\right]$ acetate. Biochem J 64, 612-620.

567. Heath H \& Wildy J (1957) Biosynthesis of ergothioneine. Nature 179, 196-197.

568. Pan L, Yu J, Ren D, et al. (2019) Metabolomic analysis of significant changes in Lactobacillus case $i$ Zhang during culturing to generation 4,000 under conditions of glucose restriction. J Dairy Sci 102, 3851-3867)

569. Pluskal T, Nakamura T, Villar-Briones A, et al. (2010) Metabolic profiling of the fission yeast $S$. pombe: quantification of compounds under different temperatures and genetic perturbation. Mol Biosyst 6, 182-198.

570. van der Hoek SA, Darbani B, Zugaj K, et al. (2019) Engineering the yeast Saccharomyces cerevisiae for the production of $\mathrm{L}-$ (+)-ergothioneine. bioRxiv, 2019, 667592.

571. Sotgia S, Zinellu A, Mangoni AA, et al. (2014) Clinical and biochemical correlates of serum L-ergothioneine concentrations in community-dwelling middle-aged and older adults. PLOS ONE 9, e84918.

572. Nishigori H, Hayashi R, Lee JW, et al. (1984) Effect of MPG on glucocorticoid-induced cataract formation in developing chick embryo. Invest Ophthalmol Vis Sci 25, 1051-1055.

573. Song TY, Yang NC, Chen CL, et al. (2017) Protective effects and possible mechanisms of ergothioneine and hispidin against methylglyoxal-induced injuries in rat pheochromocytoma cells. Oxid Med Cell Longev 2017, 4824371.

574. Guijarro MV, Indart A, Aruoma OI, et al. (2002) Effects of ergothioneine on diabetic embryopathy in pregnant rats. Food Chem Toxicol 40, 1751-1755.

575. Öztürkler Y, Yildiz S, Güngör O, et al. (2010) The effects of $\mathrm{L}$-ergothioneine and $\mathrm{L}$-ascorbic acid on the in vitro maturation (IVM) and embryonic development (IVC) of sheep oocytes. Kafkas Universitesi Veteriner Fakultesi Dergisi 16, 757-763.
576. Zullo G, Albero G, Neglia G, et al. (2016) L-Ergothioneine supplementation during culture improves quality of bovine in vitro-produced embryos. Theriogenology 85, 688-697.

577. Moncaster JA, Walsh DT, Gentleman SM, et al. (2002) Ergothioneine treatment protects neurons against $\mathrm{N}$-methylD-aspartate excitotoxicity in an in vivo rat retinal model. Neurosci Lett 328, 55-59.

578. Kawano H, Higuchi F, Mayumi T, et al. (1982) Studies on ergothioneine. VII. Some effects on ergothioneine on glycolytic metabolism in red blood cells from rats. Chem Pharm Bull (Tokyo) 30, 2611-2613.

579. Kimura C, Nukina M, Igarashi K, et al. (2005) $\beta$-Hydroxyergothioneine, a new ergothioneine derivative from the mushroom Lyophyllum connatum, and its protective activity against carbon tetrachloride-induced injury in primary culture hepatocytes. Biosci Biotechnol Biochem 69, 357-363.

580. Yoshida S, Shime H, Funami K, et al. (2017) The anti-oxidant ergothioneine augments the immunomodulatory function of TLR agonists by direct action on macrophages. PLOS ONE 12, e0169360.

581. Yoshida S, Shime H, Matsumoto M, et al. (2019) Anti-oxidative amino acid L-ergothioneine modulates the tumor microenvironment to facilitate adjuvant vaccine immunotherapy. Front Immunol 10, 671.

582. Shinozaki Y, Furuichi K, Toyama T, et al. (2017) Impairment of the carnitine/organic cation transporter L-ergothioneine axis is mediated by intestinal transporter dysfunction in chronic kidney disease. Kidney Int 92, 1356-1369.

583. Menna P, Salvatorelli E, Giampietro R, et al. (2002) Doxorubicin-dependent reduction of ferrylmyoglobin and inhibition of lipid peroxidation: implications for cardiotoxicity of anticancer anthracyclines. Chem Res Toxicol 15, 1179-1189.

584. Song TY, Lin HC, Chen CL, et al. (2014) Ergothioneine and melatonin attenuate oxidative stress and protect against learning and memory deficits in C57BL/6J mice treated with D-galactose. Free Radic Res 48, 1049-1060.

585. Motohashi N, Mori I, Sugiura Y, et al. (1974) Metal complexes of ergothioneine. Chem Pharmaceut Bull 22, 654-657.

586. Motohashi N, Mori I \& Sugiura Y (1976) Complexing of copper-ion by ergothioneine. Chem Pharmaceut Bull 24, $2364-2368$

587. Rabenstein DL \& Isab AA (1982) A proton nuclear magnetic resonance study of the interaction of mercury with intact human erythrocytes. Biochim Biophys Acta 721, 374-384.

588. Hartman PE \& Citardi MJ (1986) Protection afforded by carnosine and by ergothioneine against bacteriophage-P22 inactivation by gamma-irradiation. Environ Mol Mutagen 8, 35-35.

589. Hartman Z, Hartman PE \& Owens RA (1986) Ergothioneine (2thiol-L-histidine betaine $=\mathrm{Et}$ ) as an antimutagen - interception of direct-acting mutagens formed from nitrosation of spermidine. Environ Mol Mutagen 8, 36-36.

590. Hartman Z \& Hartman PE (1987) Interception of some directacting mutagens by ergothioneine. Environ Mol Mutagen 10, $3-15$.

591. Hartman PE, Hartman Z \& Citardi MJ (1988) Ergothioneine, histidine, and two naturally occurring histidine dipeptides as radioprotectors against $\gamma$-irradiation inactivation of bacteriophages T4 and P22. Radiat Res 114, 319-330.

592. Ishimoto T, Nakamichi N, Hosotani H, et al. (2014) Organic cation transporter-mediated ergothioneine uptake in mouse neural progenitor cells suppresses proliferation and promotes differentiation into neurons. PLOS ONE 9, e89434.

593. Misiti F, Castagnola M, Zuppi C, et al. (2001) Role of ergothioneine on $S$-nitrosoglutathione catabolism. Biochem J 356, 799-804. 
594. Ishimoto T, Masuo Y, Kato Y, et al. (2019) Ergothioneineinduced neuronal differentiation is mediated through activation of S6K1 and neurotrophin 4/5-TrkB signaling in murine neural stem cells. Cell Signal 53, 269-280.

595. Chaves NA, Alegria TGP, Dantas LS, et al. (2019) Impaired antioxidant capacity causes a disruption of metabolic homeostasis in sickle erythrocytes. Free Radic Biol Med 141, 34-46.
596. Mann T \& Leone E (1953) Studies on the metabolism of semen. 8. Ergothioneine as a normal constituent of boar seminal plasma. Purification and crystallization. Site of formation and function. Biochem J 53, 140-148.

597. Williamson RD, McCarthy FP, Manna S, et al. (2020) L-(+)Ergothioneine significantly improves the clinical characteristics of preeclampsia in the reduced uterine perfusion pressure rat model. Hypertension 75, 561-568. 